\title{
Kommentare
}

\section{Janet Halley}

\section{Vergewaltigung in Berlin}

\section{Neue Überlegungen zur Kriminalisierung von Vergewaltigung im Kriegsvölkerrecht ${ }^{1}$}

Als die Vereinten Nationen die Einrichtung eines Ad-hoc-Tribunals zur Verfolgung von Verstößen gegen die Genfer Konventionen, von Kriegsverbrechen und von Verbrechen gegen die Menschlichkeit im Balkankonflikt beschlossen, hatten Feminist_innen zunächst ein ganz einfaches Ziel vor Augen, nämlich Vergewaltigung ausdrücklich in die normierte Zuständigkeit des Gerichts einzubeziehen und die konsequente strafrechtliche Verfolgung zu sichern. Als dann die Verhandlungen über das Römische Statut im Gange waren, hatten sie eine elaborierte Agenda, die darauf abzielte, ein breites Spektrum von sexuellen Gewalttaten in den jeweiligen Einzeltatenkatalogen aller Kategorien der Verbrechen gegen humanitäres Völkerrecht (HVR) aufzunehmen; einige versuchten sogar, sexuelle Gewaltverbrechen zu eigenständigen völkerstrafrechtlichen Verbrechen zu machen, die unter keine übergeordnete Verbrechenskategorie zu subsumieren seien. Dieser Aspekt der feministischen Vision kann einerseits als Versuch verstanden werden, sexuelle Gewaltverbrechen in der Hierarchie der HVR-und der völkerstrafrechtlichen Verbrechen „nach oben“ zu rücken. Wir können es uns als das vertikale Reformprojekt vorstellen. Es wurde durch ein horizontales Reformprojekt begleitet, das darauf abzielte, sexuelle Übergriffe auf Frauen nicht nur für die Verfolgung auf höchster Ebene, sondern auch für eine separate Verfolgung zu isolieren. ${ }^{2}$

Dieser Wechsel vom anfänglichen Projekt der „Sichtbarmachung von Vergewaltigung“ zum Projekt „Eigenständige Einzeltat”“ bedeutete eine entscheidende Veränderung in der Art und Weise, wie Feminist_innen die kategoriale Beziehung zwischen bewaffnetem Konflikt und der damit verbundenen sexuellen Gewalt strukturierten. Um es offen zu sagen: Vergewaltigung sichtbar zu machen bedeutete, sexuelle Übergriffe im Krieg zu verorten - wohingegen die Erfassung von sexueller Gewalt als eigenständige Einzeltat bedeutete, Vergewaltigung als Krieg neu zu klassifizieren. Ersteres brachte die Vergewaltigung von Frauen in sichtbare Nähe zum Tod von Männern; Letzteres machte die Vergewaltigung von Frauen zur Ausnahme, sonderte sie von anderen Aspekten des jeweiligen bewaffneten Konflikts ab und richtete die Verfolgung, Verurteilung und Bestrafung allein auf die Vergewaltigung. Beide Projekte arbeiten mit der von mir so genannten Krieg/Vergewaltigung-Antinomie, aber sie handhaben diese auf sehr

1 Dieser Aufsatz basiert auf meinem Artikel: Rape in Berlin: Reconsidering the Criminalisation of Rape in the International Law of Armed Conflict, 9 Melbourne J of International Law 78, 2008. Mein Dank gilt Ciaran Cronin und Rebekka Wiemann für die Übersetzung sowie dem Harvard Law School Dean's Fund für den finanziellen Beitrag hierzu.

2 Für eine Diskussion dieser Strategie vgl. Halley et al., From the International to the Local in Feminist Legal Responses to Rape, Prostitution/Sex Work and Sex Trafficking: Four Studies in Contemporary Governance Feminism, 29 Harvard Journal of Law and Gender 335, 2006, S. 380-1. 
unterschiedliche Art und Weise. Ein starker Trend im feministischen, vertikalen

Reformprojekt in den 1990er Jahren bestand darin, diese Antinomie in Richtung Vergewaltigung zu verschieben, Krieg durch Betonung von Vergewaltigung zu verdrängen und Vergewaltigung durch Verdrängung von Krieg zu betonen. Das bedeutete beispielsweise, den Balkankonflikt als „Krieg gegen Frauen“ zu verstehen und ihn als eine Fortsetzung von Vergewaltigung im Alltagsleben zu erfassen - ein Leben, das nur in Anführungszeichen als „Friedenszeit“ bezeichnet werden kann.

\section{Eine Frau in Berlin als literarischer Text}

Eine Frau in Berlin präsentiert sich als das Tagebuch einer deutschen Frau, die bei der Kapitulation von Berlin an die Sowjets 1945 um ihr Überleben kämpft. Die chronologisch geordneten Einträge beginnen um 16:00 Uhr am Freitag, den 20. April 1945, und erzählen von den Ereignissen in der Zeitform der Gegenwart; beim Lesen werden wir eingeweiht in den geschriebenen „stream of consciousness" der Erlebnisse der Autorin.

Die Form des Buches war ausschlaggebend für zwei Wellen von Kontroversen, die es in Deutschland ausgelöst hat - die erste anlässlich der deutschen Erstausgabe im Jahr 1959 und eine weitere anlässlich der Neuausgabe 2003. Auf dem Spiel stand beide Male die Beziehung zwischen der Wahrhaftigkeit des Buches und seiner moralischen Bedeutung: Falls es wahr ist, ist es eine moralische Verurteilung der Sowjets (wegen Vergewaltigung), der Nazis (für die deutsche nationale Katastrophe), der Frau (weil sie vergewaltigt wurde), der deutschen Männer (weil sie ihre Vergewaltigung zugelassen haben). Falls es unwahr ist, ist es Anti-Sowjet-, Pro-Nazi-Propaganda, ein Angriff auf die Ehre der deutschen Frauen und die Männlichkeit von deutschen Männern (1959) - oder Anti-Sowjet-, Pro-Nazi-Propaganda oder eine Beteuerung von deutschen Leiden während des Krieges, in dem so viel Leid von deutscher Aggression ausgelöst wurde (2003). Von Anfang an stand die Herkunft des Buchs im Zentrum dieser Kontroversen. Das Literarische des Textes ist in diesen Debatten untrennbar mit seiner Unwabrheit verbunden. Und wenn literarisch, aber unwahr, so ist das Tagebuch durch obskure ideologische Besetzungen motiviert, die durch die Interpretation ausgegraben werden sollten; wenn naiv, aber wahr, so erteilt es uns unverdünnte Lektionen gleichsam in Form eines unmittelbaren Aperçus.

In diesem Abschnitt werde ich die Geschichte der zweiten Welle von Kontroversen erzählen, um das Buch fest im Kontext seiner bekannten Herkunft zu verorten. Letztendlich ist es mein Ziel, die enge Beziehung zwischen Wahrheit und moralischer Gewissheit bzw. zwischen literarischer Kunstfertigkeit und ideologischem Anstrich aufzulösen. Eine Frau in Berlin ist ein besseres Buch als das, d. h., es ist ein literarisch anspruchsvolleres Buch.

Das Tagebuch hat eine komplexe Veröffentlichungsgeschichte, die ich in der Fußnote ausführlich darlege. ${ }^{3}$ Es ist im Grunde in zwei Versionen erschienen:

3 Hier die englischsprachigen und deutschsprachigen Versionen in chronologischer Reihenfolge: 1. Erste Version: a. Anonymous. A Woman in Berlin (J. Steen Übers., 1954). Die Einleitung zu dieser Ausgabe wurde von C. W. Ceram verfasst. C. W. Ceram ist das anerkannte Pseudonym von Kurt M. Marek (vgl. Nachruf, C. W. Ceram of ,Gods, Graves and Scholars' dies, The New York Times (New York, US) 13. April 1972, S. 46). b. Anonymous. A Woman in Berlin (J. Steen Übers.) London, 1955. Die Einleitung zu dieser Ausgabe wurde auch von C. W. Ceram verfasst. c. Anonyma. Eine Frau in Berlin, mit einem Nachwort von Kurt W. Marek, Genf, 1959. 2. Zweite Version: a. Anonyma, Eine Frau in Berlin: Tagebuchaufzeichnungen vom 20. April bis 22. Juni 1945, mit einem Nachwort von Kurt W. Marek, Frankfurt 
die erste in englischer und dann in deutscher Sprache Mitte bis Ende der 1950er Jahre; und eine neue englische Übersetzung im Jahr 2005. Ich werde diese zusammen die erste bzw. die zweite Version nennen. Die erste Version wurde von Kurt W. Marek herausgegeben und mit einem Vorwort eingeleitet, die zweite von Hans Magnus Enzensberger. Beide Herausgeber haben postuliert, dass das veröffentlichte Tagebuch die genaue Niederschrift des zeitgleich verfassten Tagebuchs ihrer anonymen Autorin darstellt. In seinem Vorwort beschreibt Marek das Manuskript - „die kurze Bleistiftnotiz ...; [das] Gemisch von Kurzschrift, Normalschrift und Geheimschrift ..., die schrecklichen Abkürzungen“ - und versichert uns, dass es tatsächlich existiert: „Während ich dies schreibe, habe ich diese Blätter vor mir. “4 Er behauptet, er kenne das Gebäude, das fast durchgehend als Wohnort der Frau im Tagebuch bezeichnet wird, und er bürgt für die Genauigkeit ihrer Beschreibungen. Und er folgert: „[E]s [handelt] sich hier also um ein Dokument, nicht um ein literarisches Erzeugnis ... Aus all diesen Umständen ergibt sich: In diesem Buch wird nichts als die Wahrheit und noch einmal die Wahrheit beschrieben. "5

Im Vorwort zur zweiten Version berichtet Enzensberger, dass die Autorin die von Marek beschriebenen Aufzeichnungen „auf grauem Kriegspapier 121 engzeilige Maschinenseiten“ abgeschrieben habe, dass „diese Seiten - beglaubigt zusammen mit den originalen Notizheften durch einen der führenden Experten für Tagebücher des 20. Jahrhunderts - als erschütternde Verurteilung“ stehen und „unsere Dokumentation von dieser Zeit“ vervollständigen. ${ }^{6}$ Der Klappentext auf dem Schutzumschlag der deutschen Ausgabe dieser zweiten Version verbindet diese Wahrhaftigkeitsbehauptungen mit der Weigerung der Autorin, ihren Namen zu verraten: Auf einem beigefügten Spruchband heißt es: „Es war der Wunsch der Verfasserin, dass ihr Name ungenannt bleibt. Schon aus diesem Grunde verbieten sich Spekulationen über ihre Identität“.

Die neue deutsche Ausgabe wurde rasch zu einem Bestseller und einem bedeutenden kritischen Erfolg. ${ }^{7}$ Aber die Beteuerungen der Herausgeber bezüglich der Echtheit des Buches, ihr Bemühen, ihm einen Mantel der Objektivität aus dem Garn der Echtzeitverfassung des Manuskripts und der Anonymität der Verfasserin zu weben, sind nicht ohne Widerspruch geblieben. Der deutsche Publizist Jens Bisky, ursprünglich ein Bewunderer des Buchs, ${ }^{8}$ warf Marek und Enzensberger bald eine lange Liste von redaktionellen Verfehlungen vor. ${ }^{9}$ Enzensberger fordere die Leser auf, seinem persönlichen Zeugnis bezüglich der Echtheit des Textes und des Charakters der Frau zu vertrauen, er habe sich ohne weitere Beweise auf die Beglaubigung durch Experten berufen und den Zugang zur Handschrift sowie zur Maschinenschrift verweigert, durch den sich das Publikum selbst ein Bild von der Authentizität der veröffentlichten Version hätte machen können. ${ }^{10}$ Bisky befasste sich eingehend mit Mareks ideologischer Biografie und

am Main, 2003 („Tagebuch“). b. Anonymous, A Woman in Berlin: Eight Weeks in the Conquered City: A Diary (P. Boehm Übers.), New York, 2005. Diese neue englische Ausgabe hat ein Vorwort von Hans Magnus Enzensberger und eine Einleitung von Antony Beevor. Dieser Aufsatz wurde unter Verwendung der englischen Übersetzungen und ihrer Anhänge geschrieben.

4 Marek, Nachwort (Fn. 3), S. 286.

5 Ebd., S. 287.

6 Enzensberger, Foreword (Fn. 3), S. x.

7 Eine Sammlung von deutschsprachigen Rezensionen findet sich auf der Internetseite: Eine Frau in Berlin: die Tageszeitung <http://www.arlindo-correia.com/eine_frau_in_berlin.html> (Abruf 23. Mai 2008).

8 J. Bisky, Kleine Fußnote zum Untergang des Abendlandes, Süddeutsche Zeitung 10. Juni 2003, S. 10.

9 J. Bisky, Wenn Jungen Weltgeschichte spielen, haben Mädchen stumme Rollen, Süddeutsche Zeitung 24. September 2003, S. 16. Der andernfalls rätselhafte Titel gibt zum Teil Biskys Zitat aus einem von Marta Hillers 1935 veröffentlichten Zeitungsartikel über Kinderspiele wieder. 
seinen möglichen Gründen, das Tagebuch zu veröffentlichen sowie den Text zu manipulieren, und stieß auf antisowjetische „propagandistische“ Motive. ${ }^{11} \mathrm{Au}$ ßerdem entdeckte er Übereinstimmungen zwischen den offen gelegten Details aus dem Leben der Frau und aus dem Lebender deutschen Journalistin Marta Hillers. Er stellte die Frage, ob Hillers die ursprüngliche Verfasserin des Tagebuchs sei. Biskys Vermutung wird seitdem als Tatsache angenommen: Bei Wikipedia wird unter dem Namen von Marta Hillers dieser die Verfassung des Tagebuchs zugeschrieben. ${ }^{12}$ Bisky hatte dagegen nur über deren Leben geschrieben: „Besaß sie, während sie ... als eine Art Kleinpropagandistin des Dritten Reiches tätig war, bereits jene innere Distanz zum Nationalsozialismus, die im Tagebuch den Ton bestimmt? Ich weiß es nicht. Sie wird wohl wie die meisten hier und da genörgelt, aber ... das Gemeinschaftsgefühl begrüßt haben ... Dieselben Gründe, die dieses junge Mädchen nach Moskau führten, mögen sie zur guten Bürgerin des Dritten Reiches gemacht haben. "13 So wohlwollend dieser Abschnitt auch sein mag, Bisky deutet darin an, dass wir unsere endgültige Beschreibung der Kapitulation von Berlin nicht bei den guten Bürgern des Dritten Reiches und den Sympathisanten der Sowjetunion suchen sollten. Eine erbitterte Kontroverse folgte. ${ }^{14}$ Enzensberger gab zahlreiche Interviews, in denen er Bisky verurteilte und die Frau verteidigte. ${ }^{15}$ Weder Enzensberger noch Hannelore Marek, die Witwe von Kurt Marek und Sachwalterin der Handschrift sowie der Maschinenschrift, bestätigten oder widersprachen Biskys Mutmaßungen zur Identität der Frau. Im Laufe der Debatte jedoch verschärften neue Akteure die Auseinandersetzung über die Echtheit und Wahrhaftigkeit der Berichte im Tagebuch und über die Rolle von politischer Ideologie bei seiner Verfassung. Ich werde zwei Beispiele nennen, eines pro und eines kontra.

Die neue englischsprachige Ausgabe, die während der durch Biskys Paukenschlag ausgelösten Kontroverse veröffentlicht wurde, enthält eine neue Einleitung, die wir meiner Ansicht nach als offizielle redaktionelle Verteidigung lesen dürfen. Der Autor ist Antony Beevor, ein renommierter Experte des Zweiten Weltkriegs in Europa; Beevors Meisterwerk, Berlin 1945: Das Ende erschien lediglich drei Jahre, bevor er eingriff, um das Tagebuch zu verteidigen. ${ }^{16}$ In seiner Einleitung spricht Beevor Bisky indirekt an: Einige hätten Zweifel an der Echtheit des Werkes angemeldet, aber Experten für persönliche Schriftstücke aus dieser Zeit hätten bestätigt, dass die Abschrift des Tagebuchs original und vollkommen echt sei. ${ }^{17} \mathrm{Im}$ Folgenden bürgt Beevor für das Tagebuch aufgrund seiner eigenen Lektüre als Experte. Mit einem Hinweis auf verfälschte Kriegstagebücher, bei deren Entlarvung er mitgewirkt hatte, folgert er: „Dennoch habe ich jeden Verdacht, den ich über Eine Frau in Berlin gehabt haben könnte, schnell verworfen. Die Wahrheit lag in der Anhäufung von genau beobachteten Details. Der Blick der namenlosen Tagebuchschreiberin war so unbeirrbar und authentisch, dass sogar der genialste Fälscher ihre Vision der Ereignisse niemals hätte nachbilden können. Ebenso bedeutend war, dass andere schriftliche und münd-

12 Wikipedia Deutsch, Marta Hillers <http://de.wikipedia.org/wiki/Marta_Hillers> (Abruf 23. Mai 2008).

13 Bisky (Fn. 9), S. 16

14 Für eine etwas tendenziöse Zusammenfassung dieser Debatte vgl. J. Raphael, Review Symposium: Silencing Reports of Sexual Assault: The Controversy over A Woman in Berlin, 12 Violence against Women 693, 2006.

15 Es gibt viele Berichte über das, was Enzensberger der Presse mitgeteilt hat, aber meines Wissens nur ein direktes Interview: Szene Kultur, Interview with Hans Magnus Enzensberger, Verdeckte Ermittlungen von Schnüfflern, Der Spiegel, 29. September 2003, S. 147.

16 A. Beevor, Berlin 1945: Das Ende, München 2002.

17 Beevor, Introduction (Fn. 3), S. xvi. 
liche Berichte, die ich während meiner Forschung über die Ereignisse in Berlin angesammelt hatte, die Wahrheit der von ihr beschriebenen Welt bestätigen. “18 Der unerschrockene und klare Schreibstil der Frau bürge für ihre Objektivität: Beevor lobt bei ihr „die enge Beziehung zwischen einem nachfragenden Geist und intellektueller Redlichkeit“. ${ }^{19}$ Er kommt dann zu dem Schluss: „Eine Fran in Berlin ist ein Kriegstagebuch wie kein anderes. Dies ist die Opferperspektive, die Perspektive einer Frau auf einen schreckenerregenden Angriff auf eine Zivilbevölkerung, gleichwohl ist ihre Darstellung durch Mut, verblüffende intellektuelle Redlichkeit und ungewöhnlich ausgeprägtes Beobachtungs- und Wahrnehmungsvermögen gekennzeichnet. Es ist einer der bedeutendsten Berichte, die je über die Auswirkungen von Krieg und Niederlage geschrieben worden sind. Es ist zugleich eines der aufschlussreichsten Beispiele von Sozialgeschichte, die man sich vorstellen kann. ${ }^{{ }^{20}}$ Diese Verteidigung legt nahe, dass die neuen Befürworter des Tagebuchs noch überzeugter von der dokumentarischen und nicht literarischen Eigenschaft geworden waren, als es Marek gewesen war.

In der Zwischenzeit wurden die Gegner noch verhärteter und zuversichtlicher bei der Zurechnung bösartiger ideologischer Motive zum Tagebuch und seinen Anhängern. In einem Brief widersprach Christoph Gottesmann einer positiven New York Times-Rezension zur englischsprachigen Ausgabe von 2005 und kritisierte den Rezensenten, weil er Biskys Artikel nicht erwähnt hatte. Die ideologische Valenz des Textes war für Gottesmann viel deutlicher als für Bisky: Der Text sei pro-Nazi. „Marta Hillers ...“, schrieb er (wobei er sich sehr selektiv auf Biskys deutlich nuancierteren Bericht bezog), „war zwar kein Mitglied der Nazipartei, hat aber für unbedeutende Zeitschriften und Zeitungen während des Dritten Reichs geschrieben und bei einer Rekrutierungsbroschüre der Marine mitgewirkt“. ${ }^{21}$ Marek war ihm ähnlich suspekt: Er „hat ein Buch mit dem Titel Wir bielten Narvik geschrieben, eine auf Tagebucheinträgen basierte Darstellung vom heldenhaften Kampf der Wehrmacht“.22

Im Kontext dieser Auseinandersetzung legten die Befürworter des Tagebuchs dieses durchwegs als direkte, unbeeinflusste dokumentarische Darstellung der tatsächlichen Ereignisse aus, als politisch objektiv und als eine - wenn nicht sogar die - herausragende Stellungnahme zum Übergriff auf deutschen Zivilisten, insbesondere auf deutsche Frauen, als Folge des sowjetischen Einmarsches in Berlin, während für Bisky „das Buch als zeithistorisches Dokument wertlos“ ist:"23 „Was ist über dieses Dokument dokumentarisch belegt? Die Tagebuch-Aufzeichnungen ... appellieren an unser moralisches Urteilsvermögen, verlangen, dass wir unsere historischen Urteile überprüfen. Das können wir aber vernünftiger Weise erst dann tun, wenn wir die Fassungen des Textes, seine Entstehungsgeschichte kennen und wissen, wer was geschrieben hat."24

Was sollten wir von dieser heftigen und emotional aufgeladenen Auseinandersetzung halten? Eine Sache scheint vollkommen klar: Angesichts dessen, was wir

Beevor, Introduction (Fn. 3), S. xvi.

Ebd., S. xvii.

Ebd., S. xxi.

C. Gottesmann, Letter: A Woman in Berlin, The New York Times, 11. September 2005, S. 6. Gottesmann kritisiert J. Kanon, My City of Ruins, The New York Times, 14. August 2005, S. 12.

2 Ebd. Marek hat tatsächlich ein entsprechendes Buch veröffentlicht: C. W. Ceram, Wir hielten Narvik, Oldenburg, 1941. Der Nachruf auf Marek in der New York Times begegnet diesem Versuch, ihm mit dem Makel der Beteiligung an Propaganda des Dritten Reichs zu versehen, mit einem Gegenargument: Es wird vorsorglich darauf hingewiesen, dass Marek in die Wehrmacht einberufen wurde und dass er das Schreiben über zeitgeschichtliche Themen für eine Karriere als Antiquitätenarchäologe aufgegeben hat, damit er frei von politischem Einfluss schreiben konnte: Nachruf (Fn. 3), S. 46.

Bisky (Fn. 9), S. 16.

Ebd. 
vor der Offenlegung der Handschrift und der Maschinenschrift wissen können, kann die Frage nicht aus sich selbst heraus beantwortet werden. Seit der allerersten Ausgabe des Buchs ist es offensichtlich gewesen, dass der veröffentlichte Text nicht mit dem ursprünglichen Tagebuch identisch ist. Marek bedauert dies: „Während ich dies schreibe, habe ich diese Blätter [das Manuskript] vor mir. Ihre Lebendigkeit, wie sie sich in der Flüchtigkeit der kurzen Bleistiftnotiz zeigt, die Erregtheit, wie sie da ausstrahlen, wo sich die Feder spreizte ... das alles verliert sich wohl in der Neutralität der gedruckten Schrift. “25

Dass die Frau zugegebenermaßen das Manuskript in die Maschinenschrift umgeschrieben hat, heißt, dass Erinnerung und literarische Kunstfertigkeit eine wichtige Rolle bei der Verfassung des ersten zusammenhängenden Textes gespielt haben. Doch selbst wenn wir das Manuskript untersuchen könnten, welches allseits als das zur damaligen Zeit verfasste anerkannt wird, wir würden ihre ersten Versuche untersuchen, ihre Erfahrungen verständlich zu machen und sie in Sprache zu übersetzen. Auch der umfangreichste Textvergleich wird nicht ausschließen können, dass das literarische Bewusstsein der Verfasserin ihr allererstes Gekritzel möglicherweise geprägt hat. Und wenn das Buch literarisch und aus diesem Grund nicht wahr ist, muss man nach den ideologischen Gründen für seine Abfassung, Überarbeitung und Verbreitung suchen.

Mir scheint, dieser faszinierende Text wird zur Krux eines falschen Dilemmas gemacht. ${ }^{26}$ Struktur gibt dieser eher randständigen Auseinandersetzung über das Tagebuch nicht sein Verhältnis zur Wahrheit bzw. Unwahrheit, sondern die bittere Problematik, die auch die Darstellungsmöglichkeiten der deutschen Erfahrung des Dritten Reichs und des Kriegs strukturiert - eine strukturelle Problematik durchdrungen von ideologischen Gegensätzen, die ihre Wurzel in deutscher Reue und Schuld wegen des Krieges in der Nachkriegszeit und im deutschen Widerstand gegen und Komplizenschaft mit der Sowjetunion vor der Wiedervereinigung hat. Im Folgenden gehe ich davon aus, dass dieses Tagebuch ein literarisches Artefakt ist. Ich habe vor mir das Motto des großen Lyrikers John Milton: „the author is ever distinguisht from the person he introduces“. ${ }^{27} \mathrm{Nach}$ diesem Motto biete ich hier an, die Frau nicht als die eigentliche in Berlin in 1945 lebende Frau zu lesen, sondern als unsere Erzählerin - als die Person, die von dieser eigentlichen Autorin eingeführt wird, um die Kapitulation von Berlin aus einer vorgestellten Perspektive darzustellen. Ich lese den Text als Text. Und ich versuche die Fragestellung dahin gehend zu ändern, dass nicht gefragt wird, ob der Text wahr oder falsch, transparent und objektiv oder konfabuliert und ideologisch suspekt ist, sondern wie er unsere Sprache strukturiert, durch die wir die Beziehung zwischen Vergewaltigung und anderen Formen von Gewalt im Krieg verstehen.

\section{Eine Frau in Berlin lesen, Vergewaltigung lesen}

In Eine Frau in Berlin lesen wir, dass mit Einbruch der Dunkelheit am ersten Tag der Besetzung der Stadt die Frau und andere Frauen in ihrem Gebäude und in

26 Andere teilen meine Ansicht: Vgl. C. Jaiser, H-Soz-u-Kult, Humboldt University, Berlin, Deutschland, Rezension zu: Anonyma: Eine Frau in Berlin, Tagebuchaufzeichnungen vom 20. April bis 22. Juni 1945 (2003) <http://hsozkult.geschichte.hu-berlin.de/rezensionen/ 2003-4-138> (Abruf 23. Mai 2008).

27 John Milton, 'An Apology against a Pamphlet Call'd A Modest Confutation of the Animadversions upon the Remonstrant against Smectymnuus' in: Don M Wolfe (Hrsg.), Complete Prose Works of John Milton - Volume 1: 1624-1642 (1953) 880 („Der Autor ist stets zu unterscheiden von der Person, die er einführt“). 
der Nachbarschaft vergewaltigt wurden - immer und immer wieder (61). ${ }^{28}$ Kein Wunder, dass Eine Frau in Berlin gewöhnlich als Geschichte über Vergewaltigung gelesen wird. ${ }^{29}$ Eine andere Lesart dieses Textes ist aber möglich: nämlich als Buch über die Zerstörung der gesellschaftlichen Welt der Frau und ihre allmähliche, stockende und schließlich nur unvollständige Ersetzung durch eine neue Welt. Nach dieser Lesart ist Vergewaltigung eingebunden in die Realität des nationalen Untergangs, der Kriegsniederlage; Vergewaltigung ist ein Bestandteil der Welt dieser Frau, nicht aber ein Metonym ihrer Welt - und schon gar nicht ihre Welt als Ganzes. ${ }^{30}$

Dies ist die Krieg/Vergewaltigung-Antinomie, die ich in meiner Einleitung beschrieben habe. Es gehört zum eigentlichen Kernthema des Buches. Das Tagebuch bezeichnet Freitag, den 27. April 1945, den Tag der sowjetischen Belagerung der Straße der Autorin, als „Tag der Katastrophe“, Tag „wilder Wirbel“ (53). Gegen 20:00 Uhr hatten Soldaten angefangen, deutsche Frauen zu vergewaltigen, die Frau nicht ausgenommen. Gleich am nächsten Tag reagiert sie mit Erleichterung, als sie ihren dritten Vergewaltiger an ihrer Tür ankommen sieht: „Eine Uniform. Schreck. Die Witwe umkrallt meinen Arm. Dann Aufatmen - es ist bloß Petka“ (70).

Es ist ein wiederkehrendes Problem, das - wie wir sehen werden - in dem Text thematisiert wird, dass die Frau in dieser Szene ihren Vergewaltiger und ihre Vergewaltigungen mit Gelassenheit, fast mit Gleichgültigkeit, akzeptiert. ${ }^{31}$ Sie berichtet von nur vier emotional durchfluteten Momenten - unverblümte Begegnungen mit der Grenze ertragbarer Gefühle -, und keiner davon hat, soweit sie betroffen ist, mit Vergewaltigung zu tun. Vielmehr beschreibt sie sie als Augenblicke, in denen sie mit dem Verlust oder Entzauberung der Möglichkeit von Gemeinschaft konfrontiert war. Mit anderen Worten ihre Augenblicke intensivsten emotionalen Leidens wiederholen die Krieg/Vergewaltigung-Antinomie. Ich werde die erste Episode für später aufheben, weil sie Sex involviert, den manche für Vergewaltigung halten würden, obwohl die Frau dies bestreitet. Der zweite Moment ereignet sich, als sie aus der Wohnung, in die sie eingezogen war, nachdem ihre eigene Wohnung „weggebombt [worden war]“, hinausgeworfen wurde (10). „Die Witwe“ und ihr Pensionsgast Herr Pauli verlangten, dass sie ausziehe, als sie keine Lebensmittel mehr von den Soldaten erbitten konnte, nachdem diese weitergezogen waren, und sie dadurch zu einer Belastung der täglichen Lebensmittelversorgung des Ad-hoc-Haushaltes wurde. Vor der Besetzung hatte sie das mit ihren Nachbarn in Luftschutzkellern geteilte gemeinschaftliche Leben genossen, zusammen mit den zufälligen Haushalten, die jeder beim Zusammenbruch der erzwungenen Häuslichkeit erfand (15-18). Als sich jedoch die Strenge ordentlicher Haushaltsführung allmählich wieder etablierte, wurde sie mit dem Verlassenwerden konfrontiert, das „Los des Waisenkindes“. Das ist eine „Hiobsbotschaft“, und sie beschreibt - wie ansonsten sehr selten das Vergießen einer Träne.

28 Im Folgenden wird aus der zweiten deutschsprachigen Ausgabe nach Seitenzahlen (in Klammern in den Text eingefügt) zitiert.

29 Vgl., z. B., R. Zucker, Es klingt wie das Letzte - Ist es aber Nicht, Die Tageszeitung, 23. Mai 2003, S. 14.

30 Vgl., z. B., W. O. Weyrauch, The Experience of Lawlessness, 10 New Criminal Law Review 415, 2007.

31 Leser haben sich vielfach mit dieser emotionalen Haltung der Frau schwer getan. In seiner Einleitung von 1955 etwa hat Marek diesen Einwand vorweggenommen: „Am erschreckendsten erscheint die Kälte, mit der sie aufzeichnet ... Befremdlich ist, daß das Buch ohne Haß ist“: Marek, Nachwort (Fn. 3), S. 288-289. Er erklärt ihren Abstand als auf Schock und Hunger beruhend, aber spätere Rezensenten haben ihn zu einer positiven, echtheitsverbürgenden Tugend uminterpretiert. Beevor beispielsweise schlussfolgert, dass "die Autorin Mut und Durchhaltevermögen aufweist, wobei ihr Bericht die enge Beziehung zwischen einem nachfragenden Geist und intellektueller Redlichkeit zeigt”: Beevor, Introduction (Fn. 3), S. xvii. 
Der dritte und der vierte Augenblick sind Momente intensiver tragischer Emp-

findsamkeit, die als spezifisch ästhetische Krisen dargestellt werden. Beide ereignen sich als die Frau so etwas wie ein Gefühl nationaler Mittäterschaft an den Vernichtungslagern und ihrer Ordentlichkeit aufkommen fühlt. Als sie das erste Mal von den „Enthüllungen“ hört, stößt sie an die Grenze ihres Durchhaltevermögens:

„Und was das Tollste ist: Alles das soll in dicken Büchern säuberlich notiert sein, eine Buchführung des Todes. Wir sind eben ein ordentliches Volk. Spätabends kam Beethoven, und damit kamen Tränen. Hab abgedrebt. Man verträgt das jetzt nicht." (244)

An einem anderen Abend hört sie weitere Berichte: Die „Ordnung und Sparsamkeit“ daran beschreibt sie als „das Gräßlichste ... Dergleichen kannte Aischylos doch nicht" (278).

Konfrontiert mit dieser Verweigerung, ihre Vergewaltigungen als eindeutigen Gegenstand ihres Kummers oder ihrer Trauer zu bezeichnen, und mit ihrer beharrlichen anderweitigen Verortung dieser Emotionen, verbleiben uns zwei Möglichkeiten, uns als Leser_innen zu verhalten. Verstehen wir das Tagebuch als Buch über Vergewaltigung, so werden wir ihre Gleichgültigkeit gegenüber ihren Vergewaltigungen als Symptom ihres emotionalen Analphabetismus, ihrer abgetöteten Empfindlichkeit und beschnittenen emotionalen Fähigkeit interpretieren. Wir können beschließen, ihrer gesamten Berichterstattung deswegen zu misstrauen oder diese Defizite als Indiz für posttraumatische Belastungsstörung, Abspaltung, Verleugnung oder Trauma zu deuten und deswegen als Teil des vergewaltigungsbedingten Schadens. Wenn wir hingegen das Tagebuch als Buch über eine Protagonistin lesen, die den schmerzlichen Untergang einer Welt und ihre allmähliche Ersetzung durch eine neue Welt erlebt, werden wir ihr vertrauen, sie sogar bewundern, weil sie nur in den wirklich wichtigen Augenblicken weint. Es ist ebenso andersherum möglich: Misstrauen wir der Empfindsamkeit der Erzählerin, so ist es ein Buch über Vergewaltigung; vertrauen wir ihr, so ist es ein Buch über Krieg.

Ich denke, diese Spannung ist ein strukturelles Problem im Tagebuch, und sie lässt die Wirkung und die Intensität, die wir ihren Vergewaltigungen zurechnen sollten, immer wieder fraglich werden. Nehmen wir zwei frühe Momente aus der Geschichte über die Besetzung ihrer Straße durch die sowjetischen Soldaten, Momente, in denen der Text die Frau in einer epiphanieähnlichen Träumerei über die Vergewaltigungen darstellt. Das erste meiner Beispiele ereignet sich, als sie schon mehrmals vergewaltigt worden ist. Beim Nacherzählen ihrer Erfahrung vermerkt sie diesen jüngsten Angriff nicht als Verletzung ihrer selbst, sondern ihrer Kleidung: „Kein Laut. Bloß als Unterzeug krachend zerreißt, knirschen unwillkürlich die Zähne. Die letzten heilen Sachen“ (74). Wie sollen wir dies verstehen? Immunisiert sie sich selbst durch jämmerliche Verleugnung? Leidet sie unter völligem Realitätsverlust? Beschäftigt sie sich mit den wirklich wichtigen Dingen in ihrem Leben, etwa Kleidung zum Tragen zu haben? Dann:

„Auf einmal Finger an meinem Mund, Gestank von Gaul und Tabak. Ich reiße die Augen auf. Geschickt klemmen die fremden Hände mir die Kiefer auseinander. Aug in Auge. Dann lässt der über mir aus seinem Mund bedächtig den angesammelten Speichel in meinen Mund tropfen. "(74) 
Dies - und nicht der wiederholt erzwungene Koitus, den sie bis hierher erlitten hat - führt zu ihrem ersten Bericht von heftig dysphorischer subjektiver Erfahrung:

„Erstarrung. Nicht Ekel, bloß Kälte. Das Rückgrat gefriert, eisige Schwindel kreisen um den Hinterkopf. Ich füble mich gleiten und fallen, tief, durch die Kissen und die Dielen bindurch. In den Boden versinken - so ist das also." (74)

Und aus dieser Reaktion heraus erwächst die erste Entscheidung, in eigener Sache zu handeln. Nachdem sie erbrochen hat (ohne zu spülen, weil Wasser knapp war und sie sich nochmals übergeben könnte) fährt sie fort:

„[Ich] fasste einen Entschluss. Ganz klar: Hier muss ein Wolf her, der mir die Wölfe vom Leib hält. Offizier, so hoch es gebt, Kommandant, General, was ich kriegen kann. Wozu habich meinen Grips ...?" (75)

Sie beschafft sich umgehend einen solchen Beschützer und muss bald mit zweien jonglieren.

Dies ist eine sehr zweideutige Geschichte. Nach einer Lesart, „kapierte“ die Tagebuchschreiberin, dass sie vergewaltigt wurde, erst als ihr - wortwörtlich - ins Gesicht gespuckt wurde. Vergewaltigt, indem einer ihr in den Mund spuckt, nimmt sie in ihren Körper gegen ihren Willen die zähflüssige Körperflüssigkeit eines Mannes auf, der sie ihr aufzwingt, um sie zu verletzen. So verstanden weist die Spucke unmissverständlich auf die Vergewaltigungen hin und bringt ihr ihre äußerst prekäre Lage zu Bewusstsein. Und nach dieser Lesart werden wir wohl denken, dass sie taktiert, um sich gerade mit dem Vokabular der Männerherrschaft zu schützen: Das Ausmaß, in dem sie völlig gefangen ist und ihr „Wolf“ nur ein vertrauterer und konstanterer Vergewaltiger sein wird, ist klar. Vergewaltigung in den Mund, ausgehandelt unter Zwangsbedingungen: Das alles ist Vergewaltigung.

Diese entsetzliche Passage lässt allerdings noch eine andere Deutung zu. Danach geht die Autorin davon aus, dass die Vergewaltigungen sie nicht tief berühren; sie waren schlimm, aber es gab Schlimmeres, nämlich dass in sie hineingespuckt wurde. Wenn wir diesen Abschnitt so verstehen, würden wir wohl auch sagen, dass das Erreichen dieses Tiefpunktes unverzüglich ihre lebenserhaltende und -bejahende Fähigkeiten hervorgerufen hat: Ihre Suche nach „einem Wolf“ ist durchtränkt von einem Willen zu überleben, einem Widerstandsgeist, einem lebhaften unternehmerischen Selbstbewusstsein, das diese Suche von der totalen Niedergeschlagenheit in dem Moment, als die Spucke in ihren Mund fiel, unterscheidet und folglich auch gewiss von den geringeren Zugeständnissen, die sie gegenüber ihren Beschützern machen musste.

Die Genrefrage wird jetzt: Ist dies eine Geschichte über Vergewaltigung oder über die Alternativen der Frau im Kontext des Krieges? Dieses Dilemma wird nochmals von der zweiten Träumerei der Frau in all seiner Gegensätzlichkeit aufgeworfen:

„Tja, mit dem wilden Drauflosschänden der ersten Tage ist es nichts mehr. Die Beute ist knapp geworden. Und auch andere Frauen sind, wie ich höre, inzwischen genau wie ich in festen Händen und Tabu.... Allgemein versucht ein jeder [russische Soldat], der nicht schon zum Abmarsch bereitsteht, etwas Festes, ihm Gehöriges zu finden, und ist bereit, dafür zu zablen. Dass es bei uns mit dem Essen elend bestellt ist, haben sie begriffen. Und die Sprache von Brot und Speck und Heringen - ibren Hauptgaben - ist international verständlich.

Mir hat der Major [ihr zweiter, Wolf“] alles Mögliche mitgebracht, ich kann nicht klagen. Unter dem Mantel trug er einen Packen Kerzen. Dazu weitere Zigarren für Pauli.... 
Herr Pauli und der Major qualmten einander freundschaftlich an, und ich saß dabei und grübelte. Dies ist eine neue Sachlage. Es lässt sich keinesfalls behaupten, dass der Major mich vergewaltigt. Ich glaube, dass ein einziges kaltes Wort von mir genügt, und er gebt und kommt nicht mehr. Also bin ich ibm freiwillig zu Diensten. Tue ich es aus Sympathie, Liebesbedürfnis? Da sei Gott vor. Einstweilen hängen mir sämtliche Mannsbilder mitsamt ibren männlichen Wünschen zum Hals heraus, kann mir überhaupt nicht vorstellen, dass ich mich noch einmal im Leben nach diesen Dingen sehnen könnte. Tue ich es für Speck, Butter, Zucker, Kerzen, Büchsenfleisch? Ein wenig bestimmt. ... Andererseits mag ich den Major, mag ibn umso mebr als Menschen, je weniger er als Mann von mir will. ... Wabrscheinlich sucht er menschliche, weibliche Ansprache mehr als das bloß Sexuelle. Und die gebe ich ibm gutwillig, ja gern. Denn unter den Mannsviechern der letzten Tage ist er doch der erträglichste Mann und Mensch. ... Mit dem Major ... lässt sich reden. Womit ich die Frage aber noch nicht beantwortet habe, ob ich mich nun als Dirne bezeichnen muß, da ich ja praktisch von meinem Körper lebe und für seine Preisgabe Lebensmittel beziehe." (130-131)

Sodann fragt sich die Frau, ob es ihr eigentlich gefällt, Prostituierte zu sein, und stellt mit Erleichterung fest, dies mit einem klaren „Nein“ beantworten zu können: „Da also hat es keine Not. Ich steige aus diesem Gewerbe, wenn ich mein derzeitiges Tun schon so nennen muß, mit tausend Freuden aus - wenn ich nur mein Essen wieder auf andere, angenehmere, meinem Stolz besser zusagende Weise verdienen kann“ (132). Sex und Gesellschaft für den Major im Austausch gegen Lebensmittel: das Kriegszeiten-Äquivalent zu einem bezahlten Job. ${ }^{32}$

Ist es aber überhaupt ein „Gewerbe“? Immerhin hat sie gerade geschrieben, dass sie ihm ihre Gesellschaft „gutwillig, ja, gern“ gibt, weil es dies (nicht Sex) ist, was er hauptsächlich will. Diese Frage bringt uns zu dem Augenblick zurück, als sie sich zum ersten Mal mit dem Major verbunden fühlte. Aus dem Text lässt sich herauslesen, dass sie beim ersten Mal den Major eigentlich vögeln wollte. Gerade einen Tag vor ihrer Träumerei über Prostitution tauchte der Major zum ersten Mal in ihrer Wohnung auf, bat um Erlaubnis, in ihr Schlafzimmer zu kommen, und trat, als sie diese nicht gab, dennoch ein. ${ }^{33}$ In diesen Abschnitten deutet die Frau deutlich an, dass sie sich daraufhin völlig machtlos fühlte, ihm irgendetwas, das er von ihr wollte, zu verweigern. Noch eine Vergewaltigung? Ein Akt der Prostitution? Nun, weder der eine Ausdruck noch der andere scheint treffend:

„Schon nimmt er meine Hand, drückte sie fest mit seinen beiden Händen und sagt, wobei ibm der Mund zittert und die Augen jämmerlich blicken: 'Verzeiben Sie mir. Ich habe so lange keine Frau mehr gehabt.

Das durfte nicht kommen. Schon liege ich mit meinem Gesicht auf seinen Knien und schluchze und beule und heule mir einmal den ganzen Jammer von der Seele. Ich spüre, wie er mein Haar streichelt. Dann Geräusch an der Tür, wir blicken beide hoch. Im Türspalt steht, ibre Kerze in der Hand, die Witwe und fragt angstvoll, was mir denn sei. Der Major und ich winken beide ab, sie siebt wohl auch, dass mir nichts Böses getan wird, ich höre die Tür wieder zuklappen.

Hab ibm dann wenig später und im Dunkeln gesagt, wie elend und wund ich bin und dass er sanft sein soll. Er war sanft und wortlos zärtlich, gab bald Rube, ließ mich schlafen." (118)

Schon am nächsten Tag hat der Major Kerzen, Fleisch und Zucker mitgebracht; und die Tagebuchschreiberin fragt sich, ob sie seine Hure ist. Ein Grund für ihre Verwirrung ist, dass, jedenfalls nach ihrer Rechnung, er sie nicht vergewaltigt hat - niemals, kein einziges Mal. Von Gewalt der extremsten und unausweichlichsten Art umgeben, ist ihr klar, dass sie und der Major sich mit Sex getröstet haben. 
Sogar ganz gutem Sex. Zum ersten Mal, seitdem die Truppen in ihre Straße einmarschierten, schläft sie die ganze Nacht durch und wacht erfrischt auf. In der Aubade am folgenden Morgen singt ihr der Major das „zauberhafte“ Ständchen „Bleib, verweile doch, du Schöne mein“ (119).

Lange bevor ihre Vergewaltigungen sie zu dieser Folge von Überlegungen führen - während des heftigsten Ansturms ganz am Anfang der sowjetischen Besetzung - führt die Frau ihre eigene Erfahrung von Vergewaltigung als Grund an, um die Vorrangstellung von Vergewaltigung unter den Kriegsverletzungen zu bestreiten:

„Was heißt Schändung? Als ich das Wort zum ersten Mal laut aussprach, Freitagabend im Keller, lief es mir eisig den Rücken herunter. Jetzt kann ich es schon denken, schon hinschreiben mit kalter Hand, ich spreche es vor mich hin, um mich an die Laute zu gewöhnen. Es klingt wie das Letzte und Äußerste, ist es aber nicht." (73)

Dies ist natürlich nicht weniger problematisch als ihre Erfahrung generell. In dieser Erfahrung tritt ihr „das Letzte und Äußerste“ niemals entgegen. Sogar ihre Augenblicke extremen persönlichen Leids - den durch den Speichel ausgelösten, ihr den Boden entziehenden Horror; der zermürbende, lähmende, kräftezehrende Mangel an Nahrung, mit denen sie und ihre Nachbarn fertig werden mussten, nachdem der Major und seine Armee ihre Straße verlassen hatten (die Details langsamen Verhungerns und des erbitterten Schnorrens um Nahrung füllen Tagebucheintragungen für fast einen Monat und bescheren dem Leser 63 besonders aufreibende Seiten) (160-276) - erreichen uns in einem Tonfall stoischen Ausharrens. In ihren schlimmsten Augenblicken empfindet sie Kälte, nicht Schmerz. ${ }^{34}$ Wenn ich richtig liege, so ist dies sowohl ein Grund ihr nicht zu trauen als auch ihr zu trauen, Vergewaltigung sowohl als vorrangiges Unrecht zu betrachten als auch nicht.

Unsere Erzählerin vermeidet Superlative, wenn es ums Leid geht, bietet uns jedoch einige bezeichnende Vergleiche. Einige Vergewaltigungen etwa sind schlimmer als andere: Ihr war völlig klar, dass die Vergewaltigung einer Jungfrau bei Weitem schlimmer als die Vergewaltigung einer erfahrenen Frau war, weil es ihr den ungehinderten Zugang zu glücklichen erotischen Erfahrungen verwehren könnte, sie vielleicht dauerhaft verbittern würde. Die Gruppenvergewaltigung von einer Frau durch zwanzig Männer - gewaltsam, nicht zärtlich - ließ sie mit „verbissenen, verfärbten Brüste[n]“ zurück, ihr Mund „wie eine blaue Pflaume“: Die Frau entsinnt sich ihrer Sprachlosigkeit bei diesem Anblick (152). Anderen Franen, die Pech hatten, ist das begegnet, was für sie „das Äußerste, das Letzte“ gewesen sein mag, nicht aber unserer Protagonistin: Eindeutig durch mindestens fünf verschiedene russische Soldaten vergewaltigt, und dann mit zwei Wölfen um Schutz verhandelt, und dies alles innerhalb von drei tumultartigen Tagen - so beschreibt sie ihre Erfahrungen niemals.

Und sie erzählt immer wieder von einem Witz, der unter den Frauen kursierte: „Lieber ein Russki auf'm Bauch als ein Ami auf'm Kopf“ $(28,241)$. Mit anderen Worten, besser von einem Soldaten der sowjetischen Besatzungsarmee vergewaltigt als Opfer eines Flächenbombardements durch die Amerikaner zu werden. Die Frau hatte nicht ganz Unrecht. Wie sie wussten, hatten die alliierten Streit- 
kräfte deutsche Städte flächendeckend bombardiert. ${ }^{35}$ Dies ist eine Ablehnung der „Schicksal-schlimmer-als-der-Tod“-Redewendung, genau wie sie selbst verstanden werden will. Oder vielleicht ist es nur das, was jedermann sagen würde, der mit dem Äußersten konfrontiert wird und darum ringt, seine zitternde Psyche vor diesem Ansturm zu schützen.

Wir haben bisher das affektive und fiktive Dilemma ermittelt, in welchem das Tagebuch Vergewaltigung verortet. Die moralische und juristische Verurteilung von Vergewaltigung als besonderer Teil des Krieges ist mit einer entsprechenden Problematik behaftet.

In den ersten Stunden der Besetzung ihrer Straße hat sich die Frau engagiert als Laienanwalt gegen Vergewaltigung betätigt. Ganz am Anfang der Besetzung, als zwei Soldaten in einen Luftschutzkeller einbrechen, wo sie und ihre Nachbarn sich versteckt halten, suchen sie nach einer Frau, um sie zu vergewaltigen. Die Tagebuchschreiberin beschwert sich bei ihrem Offizier, und er informiert, ganz korrekt, seine Männer über den „Ukas Stalina“, der „sowas“ verbietet $(60,62)$. Einer der Soldaten war wütend: „Was denn? Wie haben's denn die Deutschen mit unseren Frauen gemacht?“ Er schreit: „Meine Schwester haben sie ...“ (62) Der Ukas gewinnt vorübergehend die Oberhand: Die Soldaten werden aus dem Keller hinausgeführt, und - etwas übereifrig - folgt die Frau ihnen hinaus, um sich zu vergewissern, dass sie weg sind. Prompt packen und vergewaltigen sie sie, ihre Nachbarn schließen die Schutzraumtür vor ihr zu (62-63). Schon am nächsten Tag hat der Ukas seine Wirkung völlig verloren. Nun, als die Frau und ihre Nachbarn zu einem sowjetischen Kommandanten gehen, um sich über die Vergewaltigungen zu beschweren und seine Hilfe zu suchen, sie zu beenden, lacht er nur: „Ach was, es hat ihnen bestimmt nichts geschadet. Unsere Männer sind alle gesund“ (64).

Wie der Ukas hier funktioniert, hat etwas Verdrehtes, Paradoxes an sich. Für den Kommandanten ist Vergewaltigung nichts mehr als „sowas“, die Kriegszeitenversion von alltäglichem Sex in all seiner Banalität. Und seine Durchsetzung der Regelung dagegen ist, so könnten wir sagen, aus diesem Grund wirkungslos, nutzlos, und zwar dermaßen, dass manche sogar sagen würden, sie sei mitschuldig. Aber für den russischen Soldaten, dessen Schwester vergewaltigt wurde, ist das Verbot mit hitziger Emotionalität besetzt: Vergewaltigung ist ein Verbrechen, und deswegen muss das, was seiner Schwester widerfahren ist, sich wiederholen. Seine rachsüchtige Wiederholung von Vergewaltigung dreht sich um seine Überzeugung, dass Vergewaltigung ein besonderes und ausgeprägtes Unrecht ist. Ja, der wütende Soldat scheint fast zu glauben, dass Vergewaltigung nicht nur sein Privileg, sondern seine Pflicht war. Der Ukas vereint in sich die Doppelstruktur des Tagebuchs im Allgemeinen: Er ist nicht nur Vergewaltigungsverbot, sondern die Bezeichnung von Vergewaltigung als Unheil par excellence. Und deswegen, in einer weiteren perversen Wendung, ist der Ukas in seiner ersten Bedeutung völlig wirkungslos, wohingegen er in seiner zweiten Bedeutung die Ereignisse antreibt - weitere Vergewaltigungen antreibt.

Die juristische Problematik hat eine weitere Dimension, nämlich Vergewaltigung mit nationalen Werten auf eine Art zu verbinden, die einen hohen Preis von Frauen - einschließlich unserer Protagonistin - verlangt, wenn immer ihre Ambiguität aufgelöst wird. 
Es wird niemals im Tagebuch erwähnt, aber bis Deutschland offiziell kapituliert hatte, oblag der Frau eine nationale Pflicht, dem Major keinen Trost zu spenden - gewissermaßen eine nationale Pflicht, keinen Trost darin zu finden, ihm Trost zu spenden. Insofern ihr Geschlechtsverkehr mit ihm nicht Vergewaltigung ist, handelt es sich wahrscheinlich um Kriegsverrat ( $\mathbb{9} 91 \mathrm{~b}$ RStGB), zumindest Kollaboration. Sie geht wortwörtlich mit dem Feind ins Bett. Falls das, was sie erlitten hat, Vergewaltigung war, war sie allerdings nicht nur ein machtloses Opfer, vielmehr stellte ihr Leiden - nach der perversen Logik des Ukas - für deutsche Soldaten einen Grund dar, den Willen zu hegen, sowjetische Frauen (wieder) zu vergewaltigen.

Gewiss: Das Deutsche Reich war vollständig besiegt; in vielerlei Hinsicht war die sowjetische Besetzung Berlins eine Befreiung. Deswegen kommt uns heute die dilemmatische Struktur der Kohabitation der Frau mit dem russischen Major wir können sie entweder als ihren Akt nationaler Illoyalität oder als Vergewaltigung lesen, nur nicht beides zugleich - abgeschwächt vor. Doch man denke nur an die Art und Weise, wie wir über Geschichten von den Affären französischer Frauen mit deutschen Soldaten während der deutschen Besetzung von Frankreich denken: Ihnen die Option des Widerstandes zuzuschreiben, heißt gleichzeitig, dessen Unterlassung als Kollaboration zu deuten. ${ }^{36} \mathrm{Nach}$ nationalistischen Normen kann nur reine Beherrschung - nur die Bezeichnung „Vergewaltigung“ - Geschlechtsverkehr von Frauen mit Kriegsgegnern erträglich machen.

Diese Abflachung des Vergewaltigung/Krieg-Dilemmas erfolgt, als die Vergewaltigungen einer deutschen Öffentlichkeit bewusst werden. Ich muss allerdings gleich hinzufügen, dass ich mit diesem Hinweis auf Deutschland nichts Spezifisches meine: Es ist schlichtweg ihre Nationalität und, als solche, liefert sie die Basis für die normative Auflösung der Problematik, die (so meine Argumentation) das Tagebuch bis zum allerletzten Eintrag strukturiert.

Dabei stellt der Text seine eigene Veröffentlichung auf sehr geschickte Art und Weise dar. Das erste „Publikum“ des Tagebuchs ist der Liebhaber der Frau, Gerd, der von der Front zurückkehrt und sie in ihrer einsamen Wohnung findet. Auf verschiedene Weise kündigt seine Reaktion beim Lesen der Notizhefte die tatsächliche Rezeption des Tagebuchs bei seiner Veröffentlichung als Buch an. Und tragischer Weise, jedenfalls aus meiner Sicht, zerbricht jede dieser Veröffentlichungen das Dilemma des Textes in zwei Teile und reduziert es zu einem Entweder/ Oder. Der Vorgang fängt innerhalb des Textes an, mit der plötzlichen und unerwarteten Rückkehr von Gerd. Die Frau ist außer sich vor Freude. Zudem bringt er Essen mit. Gesellig, wie sie ist, lädt sie die Witwe nach oben ein, um ihre erste Mahlzeit mit ihrem Liebhaber - ihre erste echte Mahlzeit seit Wochen - zu teilen. Um zu verstehen, was als Nächstes passiert, müssen wir zurückschauen. Während der ersten Tage der Besetzung haben die Frau und ihr erster „Wolf“ die Witwe dazu überredet, sich von einem Mann vergewaltigen zu lassen, der so heftig gedroht hat, dass er allen Grauen einflößte. Die Szene: Die Wohnung der Witwe, die Frau auf die Bettkante neben Anatol, einem ihrer Wölfe, sitzend.

„Ich sitze neben Anatol ... alsplötzlich die Tür aufgeht ... und belästigt blickt Anatol auf. Es ist die Witwe, ganz rot im Gesicht, mit verwirrtem Haar. Hinter ibr drängt sich ein Russe herein, ich kenne ibn, entsinne mich: Er ist der bübsche Pole aus Lemberg, der mit dem Kopfschuß bei Stalingrad und dem besonderen Talent für Wutanfälle. Es scheint, daß er auf dem besten Wege ist, einen solchen Wutanfall zu kriegen. Er schreit gleich los, wobei er sich sowohl an mich wie auch an Anatol 
wendet, uns beide zu Schiedsrichtern anrufend: Er sei ein junger Mensch, was anderen recht sei, sei ibm billig, er habe eine ganze Zeitlang keine Frau gehabt ... es sei doch gleich getan! Und er reißt die Augen auf, ballt Fäuste, schüttelt sein Haar - Offenbar völlig von seinem guten Recht auf die Witwe durchdrungen... Während die Witwe sich die rennenden Tränen wischt.

Anatol siebt mich an, sieht die Witwe an, will sichtlich nichts mit der Sache zu tun baben. Er meint, zu mir gewandt, das sei doch nicht so wichtig, ich solle der Witwe zureden, es seija schnell vorüber, sie möge sich keinen Ärger machen. Dann zu dem Polen, abwinkend: Man solle ibn gefälligst damit verschonen, er habe es eilig, müsse bald weiter. ... Hastig flüstre ich der Witwe ein paar Worte zu, erinnere sie an den Kopfschuß und den Wutkoller des Polen. Der Kerl ist imstande und spielt verrückt, wenn er seinen Willen nicht bekommt ... Und Anatol wird bald weg sein, der wird dann nicht belfen können ... Oder will die Witwe vielleicht Herrn Pauli wecken, auf daß er den Lemberger vergraulte [ein grotesker Vorschlag: Bis hierhin im Tagebuch hat Pauli nichts getan, um jemand vor etwas zu schützen]? Die Witwe winkt $a b, n e i n, w o z u$ ? Und sie weint. Der Pole, schon wieder besänftigt, streichelte sie. Die beiden entschwinden. "(141-142; erste vier Auslassungszeichen hinzugefügt)

Unmittelbar nach jener Vergewaltigung passiert Folgendes:

„Den ganzen Nachmittag hindurch sprach die Witwe nicht mit mir. Sie grollte. Erst gegen Abend lenkte sie wieder ein, erzäblte ... Demnach war der jugendliche Wutdeibel zahm und friedlich, ja von ermüdender Langweiligkeit, bevor er die Witwe freigab. Übrigens hatte er ibr ein Kompliment hinterlassen, erst wollte sie nicht damit herausrücken, doch schließlich gab sie es uns preis: ,Ukrainerfrau - so. Du - so.' Wobei das erste, so' durch einen Kreis aus zwei Daumen und Zeigefingern illustriert wird, das zweite ,so' durch ein Kreisen aus einem Daumen und einem Zeigefinger." (142-143)

Fortan erzählte die Witwe die „Ukrainerfrau - so. Du - so“-Scherz jedes Mal, wenn die Frauen sich trafen, um über die Vergewaltigungen zu reden (und die Frauen haben ständig über die Vergewaltigungen geredet). Die Erfahrung, die die Frau nach dem Krieg machen würde, wenn sie deutschen Männern von den Vergewaltigungen erzählen würde, fangen mit dem kleinen festlichen Abendessen für Gerd an. Die Witwe plauderte nochmals ihren kleinen Witz aus - nur diesmal war es alles andere als witzig: „Ich sah, dass Gerd befremdet war“ (279). Später [w] ar ich aufgekratzt, gab ich Stories zum besten, wie wir sie in den letzten Wochen erlebt haben, so kam es nachher erst recht zum Streit. Gerd: „Ihr seid schamlos wie die Hündinnen geworden, ihr alle miteinander hier im Haus“.... Er verzog angewidert sein Gesicht: „Es ist entsetzlich, mit euch umzugehen ..." (280)

Bald danach zeigt die Frau Gerd ihre Tagebücher (281). Während wir lesen, wie er das Manuskript des Textes liest, könnten wir wohl den Eindruck gewinnen, dass etwas Literarisches geschieht. Er liest den Text, wir lesen den Text, in welchem er ihn liest; wir lesen darüber, wie er unsere Seiten liest. Er wird zu dem, was Kunsthistoriker eine Repoussoir-Figur nennen, nämlich die kleine Person da drinnen, links oder rechts im Vordergrund, sein Rücken uns zu gewandt, die auch die große - und es ist wichtig hinzuzufügen: gemalte - Landschaft betrachtet, die wir sehen. Er erinnert uns daran, dass die Landschaft eingerabmt und betrachtet wird; er verdoppelt unsere Perspektive darauf; er verleiht dem Künstlichen eine Skala; er gewöhnt uns an unseren Platz als Betrachter. Und weil das Tagebuch eine Fiktion und kein Gemälde ist, lernen wir etwas über seine Reaktionen auf das, was er - und wir - lesen und über den Vorgriff des Textes auf seine eigene Rezeption.

Unheimlicherweise - hier haben wir ein zusätzliches Zeugnis von den literarischen Fähigkeiten unserer Autorin - sagt Gerds Reaktion sehr treffend voraus, was nach der ersten Veröffentlichunig des Tagebuchs in deutscher Sprache 1959 
passieren würde. Gereizt beanstandet er die schwer zu lesenden Kritzeleien, Notizen und Abkürzungen, die wir so gerne in unseren Händen hätten:

„'Was soll das zum Beispiel heißen?' fragte er und deutete auf ,Schdg.'

Ich musste lachen: , Na, doch natürlich Schändung. 'Er sab mich an, als ob ich verrïckt sei, sagte nichts mebr.

Seit gestern ist er wieder fort. ... Ich weiß nicht, ob er wiederkommt. " (281)

Diese Szene erscheint im letzten Eintrag des Tagebuchs. Wir erfahren nicht, ob Gerd jemals zurückkehrt.

Gerds rasch wachsender Abscheu richtet sich nicht gegen die Vergewaltigungen als solche, sondern, so scheint es mir, gegen die Einstellung der Frauen dazu. Wir sollen verstehen, er wäre im Reinen mit sich gewesen, hätten sich die Frau und ihre Nachbarinnen durch die Vergewaltigungen als völlig zerstört erwiesen - wie es einige Frauen tatsächlich waren. Es waren die Witze, die Geschichten, das Gelächter, die lässige Reduktion auf eine handliche Abkürzung, was er so abstoßend fand. Es ist „schamlos“. Wir sehen, wie Gerd die eine Hälfte des Dilemmas des Tagebuchs abschlägt. Wenn ihre Vergewaltigungen „das Äußerste“ gewesen wären, wäre ihre nationale Solidarität mit den besiegten deutschen Soldaten intakt geblieben, und Gerd wäre nicht abgestoßen gewesen. Wenn sie und die anderen Frauen stattdessen einige der Vergewaltigungen auf die leichte Schulter nahmen, wenn auch nur im Scherz, als einen von vielen Kriegsschäden, wurden sie „schamlos“, „anwidernd“ und - wie wir sehen werden - national illoyal. Jede dieser Möglichkeiten ist im Laufe der schwierigen Geschichte des Tagebuchs als Buch aufgetreten. Als Eine Frau in Berlin zum ersten Mal 1959 auf Deutsch erschien, haben deutsche Leser es entweder ignoriert oder geschmäht. Laut Enzensberger war ein Einwand die „schamlose Immoralität“ der Autorin; laut Beevor hat eine andere Rezension ihr vorgeworfen, ihre Geschichte ziehe "die Ehre der deutschen Frauen in den Schmutz". ${ }^{37}$

Und als, wie wir ebenfalls gesehen haben, das Tagebuch 2003 in einer neuen, angeblich nicht editierten deutschen Ausgabe neu aufgelegt wurde, wurde es zu einem rauschenden Bestseller in Deutschland. Für Enzensberger, den Herausgeber, war die Veränderung eine Folge der Entwicklung des deutschen Nachkriegsempfindens: Deutschland war bislang noch nicht, aber nun „bereit dafür“. Enzensberger erklärt die Veränderung als Wiederbelebung des Interesses der Deutschen an dem, was Deutsche während des Krieges erlitten haben. Er deutet an, dass jetzt

„Fragen, die früher tabu waren, erörtert werden können. Themen wie die weitverbreitete Kollaboration in Frankreich, in den Niederlanden und anderswo; Antisemitismus in Polen; die flächendeckende Bombardierung von Zivilbevölkerungen; ethnische Säuberung im Nachkriegseuropa - Themen, die viele Jahre lang von dem deutschen Völkermord in den Schatten gestellt worden sind - waren jetzt legitime Themenkomplexe. Freilich sind dies komplexe und moralisch ambivalente Themen, die leicht von Revisionisten vereinnahmt werden; nichtsdestotrotz gehören sie auf die historische Agenda und verdienen nüchterne Diskussion. Und es ist dieser Zusammenhang, in dem Eine Frau in Berlin gelesen werden sollte. "38

In Enzensbergers Sicht fügt das Tagebuch Vergewaltigung zu unserem Bild der (zugegebenermaßen komplexen) Opferrolle von Deutschen während des Krieges hinzu. Aber die Vergewaltigungen als solche sind nicht komplex, jedenfalls laut Enzensberger nicht: Sie sind einfach das, Vergewaltigungen. Die Frauen, die sie 
erlitten haben, waren vollkommen außerhalb des Kreislaufs der moralischen Ambivalenz, der die Männer gefangen hielt, die für gute und schlechte $Z$ wecke gekämpft und gestorben waren: „Es waren die Frauen, die eine Oase von gesundem Verstand in einer aus den Fugen geratenen Welt aufrechterhalten haben. Während die Männer einen mörderischen Krieg führten, erwiesen sich die Frauen als die wahren Heldinnen des Überlebens". 39

Von Interesse ist an dieser Stelle die sehr unterschiedliche Einstellung von Beevor, dem Historiker und Autor von Stalingrad und von Berlin 1945: Das Ende, dessen Verdienst es in erster Linie ist, die Opferrolle auf beiden Seiten als Teil eines Vergeltungszyklus dargestellt zu haben. Für ihn haben die Vergewaltigungen der Frauen nichts mit den einfachen Opferrollenepisoden zu tun, die uns Enzensberger vorstellt: Stattdessen räumt seine englischsprachige Einführung zur englischen Ausgabe von 2005 ein, dass das Tagebuch die sexuelle Begegnung von deutschen Frauen mit sowjetischen Soldaten als eine höchst unterschiedliche, komplexe und moralisch ambivalente Reihe von Ereignissen darstellt. ${ }^{40}$

Enzensbergers Lesart des Tagebuchs ist nicht weniger einseitig als diejenige, die von Gerd und den deutschen Rezensenten der ersten Ausgabe angeboten wurde. Jeder wählt eine Hälfte des strukturellen Dilemmas, welches, so meine Argumentation, diesen kleinen Band zu einem derart besonderen literarischen Ereignis macht. Als Literatur gelesen weist das Tagebuch darauf hin, dass der Diskurs der Äquivalente, welcher Vergewaltigung eine Vorrangstellung und eine Lauterkeit inmitten der Tötung und Zerstörung des Kriegs einräumt, sowohl die politische als auch die moralische Doppeldeutigkeit von sexueller Gewalt, sexueller Lust und dem sexuellen Zusammenkommen von Zivilisten und bewaffneten Kämpfern abflacht. Und er bringt die extreme moralische Doppeldeutigkeit von Krieg - die anhaltendste Form von legitimer Gewalt - als solche zum Einsturz.

\section{Die Politik der Kriminalisierung von Vergewaltigung im bumanitären Völkerrecht nochmals überdenken}

Feminist_innen, die sich für eine möglichst spezifische Kriminalisierung von Vergewaltigung und für eine höchstmögliche Einstufung von Vergewaltigung in der Hierarchie der HVR-Verbote einsetzen, haben damit Verfolgungsstrategien, die diese Verbrechen bevorzugt behandeln, mit der Begründung unterstützt, dass diese Reformen für die Anerkennung der Schädlichkeit und Verwerflichkeit von Vergewaltigung im Krieg durch das HVR notwendig seien. Feminist_innen wollen HVR daran hindern, das Versäumnis des Nürnberger Prozesses zu wiederholen, durch welches Vergewaltigung lediglich als Hinweis auf andere Verbrechen behandelt wurde. Bestenfalls wurde durch dieses Versäumnis eine Gelegenheit verpasst, eine der auffälligsten Formen des Übergriffs auf die Zivilbevölkerung durch die Wehrmacht zu ächten und zu bestrafen; schlimmstenfalls wurde stillschweigend angenommen, dass Vergewaltigung eine natürliche oder unausweichliche Folge des Krieges war - nichts anderes als „sowas“. Gegen dieses Versäumnis des HVR haben Feminist_innen Teilerfolge errungen: Vergewaltigung, sexuelle Gewalt und Zwangsprostitution sind in der Hierarchie der HVRund der völkerstrafrechtlichen Verbrechen „nach oben“ gerückt, vom bloßen 
Beweismittel zu benannten Tatbeständen; und mehrere ICTY-, ${ }^{41}$ ICTR-42 und IStGH-Strafverfolgungen haben sich - entweder ausschließlich oder mit deutlichem Schwerpunkt - auf die sexuellen Übergriffe konzentriert, welche in den Annalen der jüngsten Kriege so zahlreich erschienen sind. Die Literatur, die diese Entwicklungen willkommen heißt, ist immens. Hilft uns der vorangegangene Exkurs zur Rezeption und zum eigentlichen Text von Eine Frau in Berlin dabei, einige Molltöne, sorgenvolle Töne, zu diesem Chor beizutragen? Meiner Meinung nach schon, und im Folgenden biete ich vier mögliche Akkorde als Beitrag zur Symphonie an.

\section{A. Vergewaltigung als Ideologie und somit als Darstellung}

Eine Frau in Berlin gewährt uns Zugang zu der Einsicht, dass Vergewaltigung, zwar real und durch und durch schlecht, aber auch unvermeidlich ideologisch ist - und folglich, dass Vergewaltigung als Darstellung untrennbar mit Vergewaltigung als Geschehen verbunden ist. Wie können wir als Recht-Fertiger diese Einsicht für unsere Arbeit nutzen? Nun, wie wir sahen, hat Beevor die historische Genauigkeit der Darstellung in Eine Frau in Berlin beglaubigt. Nehmen wir einmal an, die im Buch geschilderten Ereignisse seien tatsächlich geschehen - wenn nicht der Frau selbst, dann irgendeiner anderen. Das Seltsame an Vergewaltigung ist, dass selbst wenn sie wirklich geschieht, sie immer auch zutiefst ideologisch ist. Man betrachte Beevors düsteren Bericht über die Reuelosigkeit der sowjetischen Soldaten gegenüber ihren an deutschen Frauen verübten Vergewaltigungen:

„In der Sowjetunion wurde das Thema so hartnäckig verdrängt, dass Kriegsveteranen sich noch heute weigern zuzugeben, was beim Sturm auf deutsches Gebiet wirklich geschah. In der Regel räumen sie ein, von einzelnen Exzessen gebört zu haben, tun das Problem aber als unvermeidliche Begleiterscheinung des Krieges ab. Nur wenige bekennen, dass sie solche Szenen selbst erlebt haben. Die kleine Hand voll, die offen dazu steht, verspürt meist keine Gewissensbisse. ,Sie haben alle für uns die Röcke gehoben und sich hingelegt', sagte der Komsomolchef einer Panzerkompanie[.] ${ }^{* 43}$

Die Fähigkeit der sowjetischen Offiziere und Soldaten, sich selbst zu überzeugen, dass die Mehrheit der Opfer entweder ihr Schicksal begrüßten oder zumindest akzeptierten, dass es nun an denen war zu erleiden, was die Wehrmacht in Russland getan hatte, ist bemerkenswert. „Unsere Jungs waren sexuell so ausgehungert”, erklärte ein sowjetischer Major damals einem britischen Reporter, „dass sie oft über alte Frauen von 60, 70 oder gar 80 Jahren herfielen - für viele dieser Großmütter eine nicht unangenehme Überraschung“. ${ }^{44}$

Wenn Beevor recht hat, dass dieses verächtliche Abtun und diese Erdichtungen abscheulich sind - und dass Eine Frau in Berlin „eines der aufschlussreichsten Beispiele von Sozialgeschichte [ist], die man sich vorstellen kann“, ${ }^{45}$ - dann haben wir ein Problem. Denn die Frau hatte ihren Rock für ihre Wölfe gehoben. Denn die Witwe war von einem sexuell ausgehungerten Soldaten vergewaltigt worden und hatte danach einen gewissen schüchternen sexuellen Stolz wegen seines dankbaren und bewundernden Kompliments über ihren Körper empfunden. Denn der Bericht der Frau bestätigt tatsächlich, dass wenigstens eine deutsche

42 International Criminal Tribunal for Rwanda (Internationaler Strafgerichtshof für Ruanda).

43 Beevor (Fn. 16), S. 44.

44 Ebd.

45 Enzensberger, Foreword (Fn. 3), S. xxi. 
Frau der Überzeugung war, dass „keines der Opfer ... das Erlittene gleich einer

Dornenkrone“ würde tragen können. „Ich wenigstens hatte das Gefühl, daß mir da etwas geschah, was eine Rechnung ausglich“. ${ }^{46}$ So auch das frappierende Motto, das dafür im Tagebuch angeboten wird: „Die Summe der Tränen bleibt konstant" (193). In anderen Worten, die Frau dachte, dass die Vergewaltigungen, die sie erlitten hat, ein genaues Äquivalent zu den von Deutschen an russischen Frauen ausgeübten Vergewaltigungen waren - äquivalent nicht nur hinsichtlich des Motivs, sondern hinsichtlich der Gerechtigkeit. Anscheinend war sie sogar der Meinung, dass dies ihre Opferrolle aufgehoben hat.

Wenn offensichtlich zusammengereimte Rechtfertigungen sich so perfekt mit unserer Darstellung des nach unserer Meinung wirklich Geschehen überschneiden, könnten wir versucht sein, die Wahrhaftigkeit der Darstellung abzuweisen und die Verlässlichkeit der Erzählerin zu bestreiten. Wie wir gesehen haben, gehen die Argumente von Bisky und Gottesmann in diese Richtung. Wir könnten sogar versucht sein, unsere Erzählerin als Komplizin der Sowjets und als Verräterin ihres eigenen Landes zu beschuldigen. Wie wir gesehen haben, nimmt Gottesmann (und vielleicht Gerd) diesen Kurs ein. Wenn wir uns aber nicht dazu verleiten lassen, wenn wir es offen lassen, dass den abstoßenden Rechtfertigungen möglicherweise echte Ereignisse zugrunde liegen - was freilich ein wenig dem Versuch ähnelt, beide, den Hasen und die Ente, gleichzeitig zu sehen -, dann bekommen wir einen flüchtigen Blick auf etwas, was selten sichtbar wird: die Wirklichkeit von Ideologie.

Aus diesem Grunde ist es meiner Meinung nach wichtig, Eine Frau in Berlin als literarischen Text zu verstehen. Damit will ich nicht sagen, es sei ein gutes Buch. Ich möchte ausdrücken, dass es bewusst und offenkundig fiktiv in dem Sinne ist, dass es seine Herstellung und dadurch die bei seiner Herstellung benutzten Materialien offen legt. Hier gibt es einen echten Gewinn sogar für die pragmatischsten Juristen unter uns. Da dieses Buch literarisch ist, gibt es zu, dass seine Darstellungen des Geschehenen - selbst wenn diese auch vollkommen zutreffend sind - Repräsentationen bleiben. Um von Vergewaltigung zu erzählen, musste sich die Autorin nämlich des vorhandenen Repertoires zur Darstellung von Vergewaltigung bedienen. Wie wir alle es tun. Im Text wird also angedeutet, dass Vergewaltigung als Darstellung zwangsläufig mit Vergewaltigung als einem Geschehen einhergeht. Die überwältigende Beredsamkeit von Vergewaltigung als Vorwurfs- und Verteidigungsdiskurs, samt all ihrer ideologischen Spezifizität, ist ständig präsent. Immer wieder lassen wird diese Allgegenwart von Darstellung außer Acht, immer wieder lassen wir sie ins Latente und Verborgene sinken aber genau in diesem Moment entgleitet uns ein wichtiger Teil von der Wirklichkeit der Vergewaltigung. Ganz gleich, wie stark Vergewaltigung kriminalisiert wird, dieses Problem ist nicht aus der Welt zu schaffen.

\section{B. Die Krieg/Vergewaltigung-Antinomie und der Diskurs der Äquivalente}

Anders als Vergewaltigung in Friedenszeiten durch deinen Freund, deinen Chef oder einen Unbekannten erfolgt Vergewaltigung im Krieg im Kontext konkreter, handgreiflicher und vorsätzlicher Gewalt. ${ }^{47}$ Das HVR betrachtet Teile dieser Gewalt als kriminell, aber eine seiner Hauptaufgaben besteht darin, den Rest zu

47 Hoffentlich ist es im vorliegenden Zusammenhang zulässig, den offensichtlichen Kritikpunkt beiseitezulassen, dass der Unterschied zwischen Gewalt im Krieg und den in Friedenszeiten typischen Machtdynamiken nicht klar feststellbar sein könne - und dass wir immer wieder zu dieser Unterscheidung zurückkehren, weil wir ahnen, dass das Berlin im frühen Mai 1945 sehr vom heutigen Berlin zu unterscheiden ist. 
legitimieren. ${ }^{48}$ Männer - und zunehmend auch Frauen - strengen sich da draußen kräftig an, einander zur töten, ihr Eigentum gegenseitig zu zerstören, ihre politischen Strukturen gegenseitig aus der Welt zu schaffen. In einem echten Krieg sterben sehr viele Menschen. Vergewaltigung unter Kriegsbedingungen verleiht dem alten Sprichwort „Vergewaltigung ist schlimmer als der Tod“ besonderen Nachdruck.

Wie oben argumentiert, liest sich Eine Frau in Berlin für mich wie ein (guter) literarischer Text, weil es dieses Sprichwort in eine Frage umkehrt und uns dann daran hindert, eine klare Antwort zu geben. Ist es besser, einen Russki auf'm Bauch als einen Ami auf'm Kopf zu haben? Im Rückblick auf ihre eigenen Vergewaltigungen haben manche deutsche Frauen eindeutig geglaubt, die Antwort auf diese Frage sei „nein“: Beevors Darstellung ist voll von glaubwürdigen Berichten, nach denen Frauen darum gebeten haben, erschossen zu werden, und sich in einer Anzahl umgebracht haben, die sogar das sowjetische Oberkommando erschreckte. ${ }^{49}$ Aber die Frau und alle ihre Freunde, denen sie ihr grimmiges Witzchen erzählte, waren anderer Meinung. Die mit Abstand am häufigsten zitierte Zeile aus dem Buch lautet: „Es [Vergewaltigung] klingt wie das Letzte und Äußerste, ist es aber nicht“ (73).

Wie ich Eine Frau in Berlin lese, erreichte die Erzählerin ihren Tiefpunkt, als der sowjetische Stallbursche ihr in den Mund spuckte - ein Übergriff, der zugleich Vergewaltigung und keine Vergewaltigung war. Emotional am belastendsten waren für sie diese Momente und als sie aus der Wohnung der Witwe herausgeworfen wurde und als sie von den Vernichtungslagern erfuhr. Der wohl aufreibendste Teil des Buches für mich als Leserin (was freilich mit meinen subjektiven Beteiligungen zu tun hat) war die lange Folge von Einträgen über ihre Anstrengungen, Essen während der Wochen zwischen dem Rückzug der sowjetischen und der Wiederkehr der deutschen Truppen zu finden, $\mathrm{zu}$ arrangieren oder $\mathrm{zu}$ sparen. Allerdings hat sie auch keinen dieser Momente als „das Schlimmste“ bezeichnet: Dass sie diesen Platz einfach unbesetzt lässt, ist eine der großen Herausforderungen des Buches.

Bei verschiedenen Versuchen, diese Problematik bei unterschiedlichen öffentlichen Anlässen zu erläutern, habe ich bemerkt, dass das Publikum darauf mit Vergleichen reagiert: Wenn Vergewaltigung nicht schlimmer als der Tod ist, heißt das, dass der Tod schlimmer als Vergewaltigung ist? Ist Verstümmelung schlimmer als Vergewaltigung oder umgekehrt? Ist Vergewaltigung schlimmer als der Tod von allen Männern deiner Familie? Als Zwangsarbeit? Als Zwangsprostitution? Als Prostitution? Meine Vermutung bei diesen Fragen ist, dass die Formel „schlimmer als der Tod“ unser Denken in einem eisernen Griff hält; unser Begriff von Vergewaltigung ist im Wesentlichen ein vergleichender. Während Feminist_innen sich mit zunehmendem Erfolg um die Aufnahme von Vergewaltigung und sexueller Gewalt in die Hierarchie von HVR- und völkerstrafrechtlichen Verbrechen bemühen, ist etwas Neues mit den normativen Begriffen geschehen, mit denen wir Vergewaltigung bewerten. Die Frage „Ist Vergewaltigung Sex oder ist sie Gewalt? “, mit der sich die angloamerikanische feministische Theorie in den letzten drei Jahrzehnten des vorigen Jahrhunderts herumgeschlagen hat, verliert an Schärfe. ${ }^{50}$ Alle sind einigermaßen damit zufrieden, sie für beides zu halten. Und 43 Columbia Journal of Transnational Law 1, 2004; David Kennedy, Of War and Law, Princeton, 2006.

50 Für eine scharfsinnige Genealogie dieser Debatte unter Feministinnen (zumindest bis zur Intervention von M. Foucault) vgl. V. Bell, Beyond the "Thorny Question": Feminism, Foucault and the Desexualization of Rape, 19 International Journal of the Sociology of Law 83, 1991. 
eine neue Frage: „Ist sie schlimmer als der Tod - und wenn nicht: als was ist sie dann schlimmer?" hat sie als Rahmenfrage verdrängt: Vergewaltigung als Diskurs der Äquivalente.

Ich würde auch vorschlagen - obwohl ich es unmöglich beweisen kann -, dass diese Entwicklung durch die Folgen der Legalisierung von Vergewaltigung im Krieg verstärkt wird. Mit Analogien und Präzedenzfällen zu argumentieren, heißt mit Vergleichen zu argumentieren. Das Ermessen bei Anklagen führt zu einer Rangordnung des Unheils. Lange Strafen erfordern Superlative. Bedeutete Nürnberg einen Diskurs der Äquivalente, in dem Vergewaltigung kaum als Unheil zählte, so verweisen die neue Rechtsprechung des ICTY und des ICTR sowie die neuen Regelungen im Umkreis des Römischen Statuts auf einen Diskurs der Äquivalente, in dem Vergewaltigung eine Rangstelle einnimmt. Wie wäre es, über die neue Stellung von Vergewaltigung im HVR oder im Völkerstrafrecht (VStR) mit der distanzierten, skeptischen Haltung zu diesem Diskurs der Äquivalente nachzudenken, die uns Eine Frau in Berlin nahelegt? Erstens könnten wir feministische Darstellungen, welche die Denkfigur von Vergewaltigung als „schlimmer als der Tod“ aufrechterhalten, mit einer gewissen Skepsis betrachten. Nehmen wir beispielsweise den Titel des von Alexandra Stiglmayer herausgegebenen Sammelbandes zur Rolle von Vergewaltigung beim Zusammenbruch des ehemaligen Jugoslawien: Massenvergewaltigung: Krieg gegen die Frauen. ${ }^{51}$ Stiglmayer erzählt, wie sie dazu kam, den Krieg auf den Balkan nicht in erster Linie als nationalen, ethnischen oder religiösen Konflikt, sondern als „Krieg gegen die Frauen“ zu betrachten. Sie beginnt, indem sie über die Interviews reflektiert, die sie mit beteiligten Frauen geführt hat. Folgendes ist ein ungekürztes Zitat aus einem ihrer Interviews :

„Wir wurden auf dem Sportplatz zusammengetrieben. Die Männer wurden in der Schule eingesperrt. Vor den Fenstern haben sie einige von ibnen in Müllcontainern verbrannt, damit der Rauch und der Gestank des verbrannten Fleisches in die Schule zieht. Vor uns haben sie die Tochter des Hodschas vergewaltigt, einer nach dem anderen hat sie vergewaltigt. Der Hodscha mußte auch zuschauen. Danach haben sie ibm ein Messer in den Hals gerammt. "52

Was erzählt uns Stiglmayer, wozu haben diese und ähnliche Geschichten sie motiviert? Sich organisiert mit Vergewaltigung zu beschäftigen, über diese zu schreiben und diese mit Nachdruck zu kriminalisieren. Die Verbrennung der Leichname der Männer ist eine Geschichte über Vergewaltigung. Das Garrottieren des Hodscha ist eine Geschichte über Vergewaltigung. Man beachte, womit das Zitat endet: Das Telos der Erzählung ist schon erreicht, bevor wir vom Schicksal der in der Schule eingeschlossenen Männer erfahren. Je mehr Vergewaltigung als Figur hervortritt, desto mehr tritt der Tod von Männern als Grund zurück. ${ }^{53}$ Vergewaltigung als ein Schicksal schlimmer als der Tod - jetzt nicht im patriarchalischen, sondern im feministischen Sinne.

An dieser Stelle haben mir viele Gesprächspartner entgegnet, nach Nürnberg sei Stiglmayers Argument ohne Weiteres nachvollziehbar. Sie mag die Betonung auf die falsche Silbe gelegt haben, doch das Problem sei gewesen, „das Leiden von Frauen sichtbar zu machen“. Und das scheint richtig. Aber dann stellt sich die Frage: Worin besteht das Leiden von Frauen? Was ist dieses Ding, das - wie wir alle meinen - sichtbar werden soll? Man kann sich dieser Frage - freilich partiell

52 A. Stiglmayer, Vorwort der Herausgeberin, in A. Stiglmayer (Hrsg.), Massenvergewaltigung, Frankfurt/ M. 1993, S. 15.

53 J.-P. Sartre, Das Sein und das Nichts, Gesammelte Werke, Philosophische Schriften Bd. 3 (H. Schöneberg, T. König Übers.), Reinbeck be Hamburg, 1993 [Übers. von: L'Etre ét le Néant], S. 17, 18. 
- nähern, indem man fragt: Was bedeutet Vergewaltigung für Frauen, die vergewaltigt wurden? Amerikanische Feminist_innen haben sich in die Situation am Balkan eingebracht, weil sie zu wissen glaubten: Die Frauen wurden zum Schweigen gebracht und brauchten HVR, um ihre Stimme als vergewaltigte Frauen zu finden. Aber nicht alle Frauen, die sie vertreten wollten, haben sich durch die Linse der amerikanischen Frauenrechtler_innen wiedererkannt. Einige haben sich an die Seite von Richterin Nusreta Siva, einer Omarska-Gefangenen, gestellt, deren Antwort weniger eindeutig ausfiel:

„Gewöhnlich stört es mich, wenn jemand von vergewaltigten Franen redet ... Vergewaltigte Frauen - es verletzt einen, als vergewaltigte Frau bezeichnet zu werden, als ob man keine andere Eigenschaft hätte, als ob dies deine einzige Identität wäre. "s4

Wenn wir Richterin Siva folgen, ist sogar die Vermutung, dass nur vergewaltigte Frauen Vergewaltigung bewerten können, falsch: Anscheinend würde sie Vergewaltigung aus der Perspektive einer ihrer anderen Identitäten bewerten wollen. Vielleicht aus der Perspektive der Identität, welcher auch immer, die unter dem Verlust der durch den Krieg getöteten und brutalisierten Männer und Jungen leidet. Oder jener, die den Verlust der Vorkriegslebenswelt - der Lebenswelt vor dem Konflikt, der zum Krieg führte - erlitten hat.

Es existiert also ein weitreichenderes Problem hinsichtlich der Stelle, die Vergewaltigung innerhalb des eigenen hartnäckigen Diskurses der Äquivalente einnimmt. Jeder, der den Tod von Männern verabscheut - und vermutlich schließt das alle ein, die sich eine größere Effektivität des HVR bei der Reduzierung der Häufigkeit und Zerstörungskraft von Krieg wünschen -, sollte Initiativen, welche Vergewaltigung eine Vorrangstellung gewähren, mit Argwohn betrachten. Ja, ein solcher Schritt sollte auf jeden, der für die legitimierende Funktion von HVR empfänglich ist, schlichtweg alarmierend wirken. Die Sowjetarmee hat ganze Dörfer in den tiefen Schnee hinaus getrieben; Schiffe mit Tausenden von Flüchtlingen am Bord torpediert; Menschen in ihren eigenen Häusern verbrannt; alle Gebäude geplündert, die sie nicht vorher zerstört haben und dabei fast den ganzen Lebensmittelvorrat beschlagnahmt; eine offizielle Keine-Gefangenen-nehmen-Politik gegenüber besiegten deutschen Soldaten beschlossen und durchgesetzt; und die nicht Getöteten zur Zwangsarbeit rekrutiert. ${ }^{55}$ Diese Kampagne als „Krieg gegen die Frauen“ zu erfassen - egal wie viele Vergewaltigungen involviert waren, und es waren Hunderttausende - wäre eine Travestie der Geschichte und ein gravierender Missbrauch der geringen Handhabe des HVR, einen Teil der Kriegsgewalt zu delegitimieren, während es den übrigen Teil legitimiert.

\section{Vergewaltigung in eine Waffe verwandeln}

Oben habe ich nur einige der während ihres Einmarsches in Deutschland von der Sowjetarmee verübten Taten aufgelistet. Diese unglaublich grausamen und zerstörerischen Taten würden wohl als ungeheuerliche Verbrechen gemäß dem heutigen HVR gelten, zumindest in der Niederschrift. Wie Beevor als Autor nicht nur von Berlin 1945: Das Ende, sondern auch von Stalingrad besonders überzeugend herausstellen konnte, hat die sowjetische Kriegsmaschine diese Taten nach dem Vorbild des unglaublich grausamen und zerstörerischen Verlaufs der 
det. ${ }^{56}$ In der Tat scheint die Frau die Kausalkette, die ihre Vergewaltigungen mit den Vergewaltigungen von sowjetischen Frauen durch Deutschen verbindet, gut begriffen zu haben.

"Meine Schwester haben sie ... “(62)

„Keins der Opfer kann das Erlittene gleich einer Dornenkrone tragen. Ich wenigstens hatte das Gefühl, daß mir da etwas geschah, was eine Rechnung ausglich".".7

Die Pointe dieses Vergleichs ist die Kluft zwischen Recht in der Niederschrift und Recht in der Anwendung. Eigentlich könnte ein gesetzliches Verbot in Kombination mit einem fast unbegrenzten Rest von toleriertem Missbrauch den Wert einer bestimmten Kategorie von Tätlichkeit als Kriegsinstrument erböben. ${ }^{58}$ Das entspricht, wie oben angedeutet, dem starken Eindruck, den Eine Frau in Berlin beim Lesen über den Augenblick der ersten Vergewaltigung der Fran auf mich gemacht hat. Dort war die Tatsache, dass die Vergewaltigung einer feindlichen Zivilistin durch einen Soldaten rechtswidrig war - in diesem Fall nach dem Ukas Stalina - nicht nur ein völlig nutzloser Schutz für die Frau, sondern auch ein starkes Motiv für ihren Angreifer. Mit anderen Worten, das intensive und spezifische Verbot von Vergewaltigung kann diese in eine Waffe verwandeln. Diese perverse Dynamik kann freilich auch ohne die Intervention des Rechts durch die unheimliche Tendenz von Rache, Gleiches mit Gleichem zu vergelten, in Gang gesetzt werden. ${ }^{59}$ Und die Krieg/Vergewaltigung-Antinomie gilt auch hier: Die Aushungerung und Enteignung der Zivilbevölkerung, das Versperren von Rückzugsgebieten für Flüchtlinge, das Zurückversetzen von Gefangenen in den nominellen Status von Kämpfern, um sie zu töten oder unter Missachtung der Genfer Konventionen oder anderer HVR/VStR-Instrumente sonstwie zu behandeln - all dies sind inzwischen eindeutige Verstöße gegen HVR/ VStR, welche - genau wie Vergewaltigung - als solche durch Recht zu Waffen verwandelt werden können, insbesondere angesichts der durch große tolerierte Missbrauchsbereiche bedingten Beeinträchtigung der Fähigkeit von HVR/VStR, viele Konfliktsituationen zu regulieren.

Dass Vergewaltigung eventuell als Waffe benutzt wird, ist allerdings einer Erwähnung wert, weil es kaum Beachtung in der Rechtfertigungsliteratur über die jüngsten feministischen Reformen sowohl in ihrer aktivistisch-advokatorischen als auch in ihrer offiziell-halboffiziellen Form findet. Entlang der Spannbreite dieser Literatur ist der Diskurs über Verbote identisch mit dem Diskurs über die „Beendigung“ von sexueller Gewalt im Krieg. ${ }^{60}$ Herzlich wenig Beachtung gewinnt die schaurige Tatsache, dass die Propaganda, die die Kosovoserben zu ethnonationaler Abspaltung und Krieg aufgerufen hat, Anschuldigungen über Vergewaltigungen von serbischen Frauen durch albanische Männer einschloss - und dass dies ein kriegsbegründender, ja kriegsprovozierender Faktor war. ${ }^{61}$ Gleichwohl hat sich die Verurteilung von Vergewaltigung durch Feminist_innen und durch das HVR/VStR als durch und durch unbeeindruckt von der Möglichkeit gezeigt, dass ihre besondere Illegalität einen weiteren vergewaltigungsgetriebenen, vergewaltigungswiederholenden Krieg antreiben könnte. Diese Gleichgül-

58 D. Kennedy, Sexual Abuse, Sexy Dressing, and the Eroticization of Domination, 26 New England Law Review 1309, 1992, S. 1341.

59 Aus diesem Grund ist Rache beinahe stets höchst literarisch.

60 Für Beispiele vgl. Halley et al. (Fn. 2), S. 426.

61 W. Bracewell, Rape in Kosovo: Masculinity and Serbian Nationalism, 6 Nations and Nationalisms 563, 2000. 
tigkeit gegenüber grundlegenden rechtsrealistischen Vorstellungen von der eigentlichen Art und Weise, wie Recht im Allgemeinen und HVR/VStR im Besonderen funktioniert, ist für mich eine der bestürzendsten Aspekte der ganzen Kampagne gewesen. Es ist, als ob Frauen niemals Schaden erleiden, wenn Männer Vergewaltigung bestrafen, weil man davon ausgeht, dass Männer Vergewaltigung niemals bestrafen. Ich möchte mit einer amüsanten - aber zugleich beunruhigenden - diesbezüglichen Anekdote schließen: Ich war einmal im Publikum - besetzt bis auf die letzten Stehplätze -, als eine prominente feministische Befürworterin einer extensiven und intensiven Verfolgung von Sexualverbrechen gegen Frauen sich beschwerte, dass noch niemals ein Krieg geführt wurde, weil ein Mann eine Frau vergewaltigt hat. Ein Raunen lief durch den Saal: „Die schöne Helena“.

\section{Die Problematik der Nötigung}

Die am ICTY-Verfahren und an den Verhandlungen über das Römische Statut beteiligten feministischen Aktivisten hatten Regelungen vor Augen, die es den Gerichten erlauben würden, Nötigung aus den Umständen von bewaffneten Konflikten zu schließen und der auf eine tatbestandsausschließende oder rechtfertigende Einwilligung plädierenden Verteidigung Grenzen zu setzen. Sie machten in dieser Richtung erhebliche Fortschritte und führten eine Reihe von im Vergleich zum US-amerikanischen Strafrecht beachtlichen Gesetzesinnovationen ein. Aber sogar die meisten Feminist_innen - und sicherlich auch das ICTY und die Verfasser der Verfabrens- und Beweisregeln des IStGH - haben die vollständige Abschaffung der Einwilligung als Argument der Verteidigung mit gemischten Gefühlen betrachtet.

Sind wir überhaupt nicht besorgt, dass sowohl die in Kunarac et al. ausgesprochenen Regeln des Fallrechts ${ }^{62}$ und die im Römischen Statut normierten völkervertraglichen Regeln (zusammen mit den in den Verfabrens- und Beweisregeln des IStGH festgelegten „Grundsätzen“) es einem ambitionierten Strafverfolger erlauben würden, den Major in Eine Frau in Berlin wegen Vergewaltigung, wegen sexueller Gewalt und vielleicht sogar wegen sexueller Versklavung anzuklagen? Es ist völlig klar, dass die Frau ihn niemals in ihr Zimmer hätte eintreten lassen und nie eine Beziehung mit ihm aufgenommen hätte, wenn die Umstände sie dazu nicht genötigt hätten. Es ist allerdings ebenso klar, dass sie Trost bei ihm suchte, dass sie beiderseitig zufriedenstellenden Geschlechtsverkehr mit ihm hatte, zufrieden neben ihm schlief, danach erfrischt aufwachte und ihn im Grunde mochte. Er war die erste gute Sache, die sie erlebte, seit die Sowjetarmee ihre Straße besetzt hatte.

Die Frau und der Major hatten eine stillschweigende Abmachung: Er schützte sie vor entschieden unfreiwilligerem Geschlechtsverkehr mit anderen Soldaten, besorgte die Lebensmittel, die sie und ihre Mitbewohner verzweifelt brauchten, brachte sogar Luxusartikel mit; im Gegenzug versorgte sie ihn mit Geschlechtsverkehr, Gesellschaft, kultivierter Konversation und einigen Annehmlichkeiten bürgerlicher Häuslichkeit. Hier nähern wir uns gefährlich einem Verständnis ihrer Beziehung zu dem Major, die diese einer gewöhnlichen Kohabitation angleicht, freilich entsprach das nicht ihrer eigenen Sichtweise: Sie betrachtete ihre Beziehung zu dem Major im Grunde als Prostitution, nicht als eine normale eheähnliche Gemeinschaft und nicht als Vergewaltigung.

Zumindest einige der Frauenrechtler_innen, welche die neuen Regelungen zu sexueller Gewalt schreiben, hatten in der Tat vor, eben solchen ausgehandelten 
Sex in den neuen Kanon der HVR-Verbrechen aufzunehmen. Der Women's

Caucus for Gender Justice (Frauenausschuss für Geschlechtergerechtigkeit) im IStGH hat beispielsweise in der Konferenz zum Römischen Statut ein Argument angeführt, welches in seinem Begriff von Zwangsprostitution, Serienvergewaltigung und sexueller Sklaverei explizit die Prostitution genau im Sinne der Abmachung der Frau mit dem Major einschloss:

„Es kann [eine] Kategorie von Zwangsprostitution geben, die weniger als sklavereiähnliche Bedingungen involviert. Frauen können dazu gezwungen werden, sich Serienvergewaltigungen zu fügen im Austausch gegen ibre Sicherbeit oder gegen die Sicherheit von anderen oder gegen die Mittel zum Überleben. Obwobl die Franen, genau genommen, keine Prostituierten wären, so wären sie aber doch zum Sex gegen etwas von Wert für einen oder mebrere Männer in einer Übermachtstellung gezwungen. Aber sogar in Fällen, in denen Frauen abends nach Hause gehen oder sogar entkommen dürfen, können die Kriegsbedingungen trotzdem so überwältigend und bestimmend sein, dass diese sie zu kaum mehr als Sexsklavinnen machen. Die Entscheidung, ob jemand wegen Zwangsprostitution, sexueller Sklaverei oder Serienvergewaltigung angeklagt werden sollte, würde von einer gründlichen Analyse der jeweiligen Fakten aus der Perspektive der Frau abhängen. "63

Wenn ein von diesem Bewusstsein geprägter Ankläger das Gesetz, wie es heute in den Beweis- und Verfabrensregeln des IStGH und Kunarac sowie im Römischen Statut oder in den in seinen Verfabrens- und Beweisregeln enthaltenen „Grundsätzen“ existiert, anwenden würde, könnte er den Major wegen einer Vielzahl von Sexualverbrechen verfolgen und ihn unter Umständen auch überführen. Durch eine genaue Analyse der Umstände der Beziehung zwischen der Frau und dem Major aus der Perspektive der Frau, wie sie in ihrem Tagebuch dokumentiert sind, könnte unser fiktiver Ankläger immerhin schlussfolgern, dass sie Zwangsprostitution, Serienvergewaltigung und sexuelle Sklaverei beweisen. Nach den Regeln, wie sie in den ICTY-Urteilen im Fall Kunarac ausgelegt sind, würden die nötigenden Umstände die Vermutung von Nötigung und Nichtzustimmung nahe legen, und der Major könnte diese Vermutung nicht durch das Zeugnis der Frau entkräften, auch dann nicht, wenn es den einschlägigen Auszügen aus dem Tagebuch genau entspräche. Angenommen er hätte eine Kopie des Tagebuchs und es wäre ihm erlaubt, es unter Ausschluss der Öffentlichkeit einzuführen, ein von der Argumentation des Women's Caucus überzeugter Richter würde sie wohl als positiven Beweis gegen ihn werten. Nach den in den Verfahrens- und Beweisregeln des IStGH dargelegten Grundsätzen müsste die Frage der Zustimmung vor Gericht entschieden werden. Allerdings dürften weder Aussagen der Frau noch ihr Verhalten als Beweis ihrer Zustimmung angeführt werden, sollte das Gericht zum Schluss kommen, dass „Gewalt, die Androhung von Gewalt, Nötigung oder die Ausnutzung eines nötigenden Umfelds die Fähigkeit des Opfers, seine freiwillige und aufrichtige Zustimmung zu geben, unterminiert hat" ${ }^{64}$ Nochmals, der Tagebucheintrag, der die Träumerei der Fran hinsichtlich des Majors festhält, könnte als direkter Beweis für eine solche „Ausnutzung eines nötigenden Umfelds“ fungieren. Sie könnte ihre Einwilligung gegeben haben, aber trotzdem könnte das Gericht zu dem Schluss kommen, dass ihre Einwilligung weder „freiwillig“ noch „aufrichtig“ war. 
In Debatten über die Reichweite von Verboten vom Sexhandel im internationalen und nationalen Recht wird Frauenrechtler_innen, welche die Linie des Women's Caucus vertreten, von anderen, häufig als Menschenrechtsaktivisten organisierten Feminist_innen, widersprochen, welche gegen den rechtlichen Ausschluss der Entscheidungen von Frauen sind, sich auf ausgehandelten Sex einzulassen. Letztere benutzen ein liberal-feministisches Vokabular, um die Entscheidungen von Frauen auch unter Bedingungen radikal ungleicher Verhandlungsmacht zu schützen. ${ }^{65}$ Ich denke, sie schöpfen die begrifflichen und rhetorischen Ressourcen für diese Interventionen aus der allgemeinen Vorstellung, dass in der internationalen Arbeitsdynamik sich Frauen und Männer in einem Markt begegnen. Es ist sehr schwierig, entsprechende Ressourcen im Vokabular des Krieges und der Kriegsverbrechen zu finden. ${ }^{66}$ Die Sowjetarmee erreichte Berlin unter Verwendung von Zwang, von vorsätzlichem Zwang; sie war auf Beherrschung aus, nicht auf Austausch. Aber ich denke, dass die durch Eine Frau in Berlin aufgezeigte Nötigungsproblematik uns die Aufgabe stellt, ein rechtlich verständliches Vokabular zu finden, durch welches die Frau die Verfolgung des Major ablehnen und der Major sich wirksam gegen diese wehren könnte.

Um die Frage ein letztes Mal in der - meiner Meinung nach hier notwendigen konsequentialistischen Begrifflichkeit zu stellen: Stellen Sie sich vor, im nächsten ethnonationalen Krieg begegneten uns nochmals jene Umstände, die zu Verurteilungen im Falle Kunarac geführt haben: Männer in Todeslagern inhaftiert; Frauen getrennt inhaftiert und immer wieder vergewaltigt; ein Kombattant von der anderen Seite überlegt sich, ob er einer inhaftierten Frau anbieten sollte, sie aus der Turnhalle, in der sie festgehalten wird, zu entlassen und sie in seine Wohnung zu bringen. Er weiß und sie weiß, wenn er dieses Angebot macht und sie es akzeptiert, dann ist abgemacht, dass sie Sex mit ihm haben und seine Wohnung sauber machen würde, dass sie ungehindert kommen und gehen dürfte; sie beide wissen, dass er zu ihrem „einsamen Wolf“ werden und sie gegen die anderen Männer schützen würde. Und nehmen wir an, dass sie, vor die Wahl gestellt, mit ihm mitzukommen, tatsächlich einwilligen würde. Glauben wir, dass er ihr dieses Angebot jemals aufgrund der neuen Regelungen im HVR/VStR nicht machen würde? Und wenn wir glauben, die neuen Regelungen könnten ihn, wenn auch nur einmal, davon abhalten, dieses Angebot auch nur ein einziges Mal nicht zu machen, weil er weiß, dass er damit ein besonderes und besonders nachdrücklich geächtetes HVR/VStR-Verbrechen begehen würde -, sind wir sicher, dass wir sie schützen, indem wir diese Abschreckung sicherstellen?

\section{E. Die Annäherung von Feminismus und Nationalismus}

Am Morgen, nachdem sich die Frau dem Major hingegeben hatte, am 2. Mai 1945, „hörte die Witwe, ... daß gegen vier Uhr die Kapitulation von Berlin unterzeichnet worden ist - jemand hatte es mit dem Detektor gehört. ,Frieden', so glaubten wir und freuten uns. Bis wir nachher erfuhren, daß in Nord und Süd der Krieg weitergeht“ (120). Das deckt sich mit Beevors Geschichte der Kapitulation, die ein stockender und schwieriger Prozess war. Nach seinem Bericht hatten nämlich einige deutsche Offiziere schon am 1. Mai 1945 kapituliert, doch setzten sich Kämpfe und intensive Verhandlungen darüber, wie, wo und unter welchen Bedingungen die offizielle, endgültige Kapitulation erfolgen sollte, bis zur Inszenierung der vollständigen Kapitulation in der Nacht vom 8. zum 9. Mai 
1945 fort. ${ }^{67}$ Die Frau hatte Gerüchte von einer endgültigen Kapitulation und Friedenserklärung am 8. Mai gehört. Als die Frau mit dem Major in ihrem Bett einschlief, hatte sie Kriegsverrat, Kollaboration begangen. Sie war Staatsbürgerin eines Kriegsstaates, der Befehle erlassen hatte, die die unverzügliche Hinrichtung jedes vor der Sowjetarmee kapitulierenden Soldaten und jedes diese unterstützenden Zivilisten vorsahen. Aber als sie und der Major aufwachten und er ihr „Bleib, verweile doch, du Schöne mein“ im hellen Morgenlicht vorsang, hatten Gerüchte von Kapitulation und Frieden den Anfang einer neuen Rechtsordnung angekündigt, die sie von ihrer Verantwortung, ihm zu widerstehen, entbinden würde. In der Zwischenzeit, in der akuten, aber vorübergehenden Abwesenheit von lokalem Recht, schwebte ihre Intimität zwischen dem gesetzlich Unerlaubtem und dem gesetzlich Erlaubtem. Gesetzlich erlaubt vielleicht, aber nicht moralisch - nicht in den Augen von Gerd. Die Wiederkehr der besiegten deutschen Soldaten hatte die kulturellen Kräfte der nationalen Solidarität wieder hergestellt: Er betrachtete sogar ihre Vergewaltigungen als unverschämte Illoyalität und bestrafte sie, indem er schweigend wegging. Wenn er von der Freude gewusst hätte, mit der sich die Frau und der Major an jenem ersten Morgen der deutschen Niederlage begrüßten, wäre er wohl noch heftiger abgestoßen gewesen.

Was würde die durch die guten Dienste des HVR und/oder des VStR verstärkte Ächtung der Affäre der Frau mit dem Major - und das Streben von Feministen, HVR/VStR unempfindlich gegenüber der Rolle ihres Willens bei dieser Beziehungsbildung zu machen - zu dieser Kaskade von nationalistischen, teilweise kriegerischen Ächtungen hinzufügen? Wie wir gesehen haben, hätten die neuen Regelungen im HVR über sexuelle Gewalt im Krieg die Liaison der Frau mit dem Major nochmals rekriminalisiert: Der Major hätte strafrechtlich verurteilt werden können, wären die jetzigen Regelungen in Kraft gewesen.

Wohlgemerkt entspricht diese Bewertung des Vergehens des Majors allerdings vollkommen der Bewertung ihres Vergehens als Kriegsverrat. Wie die Regelungen des Dritten Reichs Soldaten verpflichtet hatten, bis zum Tode zu kämpfen, und Zivilisten, Widerstand bis zum Äußersten zu leisten, setzen die neuen HVR/ VStR-Regelungen eine Feindseligkeit im bewaffneten Konflikt zwischen bewaffneten Kämpfern auf der einen Seite und Zivilisten auf der anderen Seite voraus. Für viele Zivilisten wäre diese Feindseligkeit ganz natürlich: Zivilisten, die aus ihren eigenen Häusern ausgebombt werden, die in sinkenden Lazarettschiffen ertrinken oder zu Sklavenarbeit gezwungen werden, würden zweifelsohne diese Feindseligkeit bestätigen - zumindest soweit persönliche Interessen auf dem Spiel stehen. Aber bekanntermaßen werden Frauen, die Sex mit feindlichen Kämpfern haben, nicht immer glauben, dass sie Opfer einer Tätlichkeit sind. Manchmal wollen sie es. Die neuen Regelungen, welche Anklagen und Verurteilungen, die diese Tatsache ignorieren, wahrscheinlicher machen, bestätigen die Verpflichtung von Zivilisten, sich feindselig gegenüber dem nationalen Feind zu verbalten. Sie verankern die Frauen, die sie schützen, in ihren Nationen. Sie rekrutieren Zivilisten für genau die Form von bewaffnetem Konflikt, die HVR im Allgemeinen missbilligt.

Eine solche Wiederverankerung lässt sich aus der Argumentation des Berufungsgerichts im Falle Kunarac herauslesen. Wie Karen Engle zeigt, hat das Gericht seine Vermutung, dass ein Opfer nicht eingewilligt hat, durch den Hinweis auf ihre Gefangenschaft und die Tatsache, dass sie auf diskriminierende Art und 
Weise nach ibrer ethnischen Herkunft ausgesucht wurde, begründet. ${ }^{68}$ Diese Tatsachen haben die juristische Schlussfolgerung unterstützt, dass die Umstände so gewaltsam waren, dass der Beweis von Nichtzustimmung vollständig erbracht war. ${ }^{69}$ In dieser Formulierung hätten die ethnischen Animositäten zwischen den Tätern (Serben) und den Opfern (bosnischen Muslimen) den serbischen Soldaten von der Annahme bzw. der rationalen Schlussfolgerung abhalten sollen, seine bosnische, muslimische Sexpartnerin habe ihre Einwilligung gegeben.

Das ist ein kleiner, aber meiner Meinung nach wichtiger Sieg für die serbische Politik der ethnischen Säuberung. Wir dürfen nicht vergessen, dass der Krieg in Bosnien-Herzegowina zur ethnonationalen Teilung einer Bevölkerung geführt hat, die zumindest in den Städten kosmopolitisch geprägt und in denen interethnische sexuelle Beziehungen und Ehen häufig sowie - wenigstens in den Städten - unkontrovers waren. An welchem Punkt in einem solchen Konflikt sollte das HVR sich auf die Seite von ethnischen Nationalisten stellen und annehmen, dass die interethnische Qualität einer solchen Begegnung Beweis von Nicht-Einwilligung ist?

Wie die Bestätigung der nationalen Pflicht der Frau, sich an ethnische Feindseligkeiten ihres durch und durch ethnonationalen Staates zu halten, so setzt diese Entscheidung in Kunarac die neue Frauenfreundlichkeit von HVR in Widerspruch zu seinem Kosmopolitismus. Es mag sein, dass die tatsächliche Anwendung von HVR in Wirklichkeit niemals nationale oder ethnonationale Feindseligkeit verstärken wird. Es mag sein, dass es nicht stärker für das Böse ist als für das Gute. Aber ich denke, dass die ausgeprägte Gleichgültigkeit der Diskussion bezüglich dieser Spannung - unter amerikanischen Feministen hat nur Engle die Kühnheit ihn anzusprechen gehabt - ein Manko ist.

\section{Schlussfolgerungen}

Eine Frau in Berlin ist - so habe ich argumentiert - eine fesselnde literarische Leistung, weil sie über die dichte Oberfläche ihres fein ziselierten Narrativs eine verdeckte Problematik aufbaut, die nicht nur zu diesem Narrativ, seiner Autorin und ihrem persönlichen Leben gehört, sondern auch zu der Sprache und den begrifflichen Mitteln, die wir gebrauchen, um sexuelle Gewalt im Krieg zu verstehen. Keines dieser in Teil III. dargelegten Probleme weist so eindeutig auf eine einzige Politik hin, dass sie unsere Wachsamkeit gegenüber Gewalt und gegenüber sexueller Gewalt innerhalb und außerhalb von Krieg vermindern sollte. Sie - und das Tagebuch - legen allerdings nahe, dass saubere Verbote in einem Netz von widersprüchlichen und höchst politisierten Bedeutungen und Begrifflichkeiten operieren, das sie nicht vollkommen überwinden können. 